\title{
Química mineral dos granitos leucocráticos do Stock Lagoa de Dentro, Sul da Província Borborema, Nordeste do Brasil
}

\author{
Mineral chemistry of the leucocratic granites of the Lagoa de Dentro Stock, Southern \\ Borborema Province, Northeastern Brazil \\ F. S. Pereira ${ }^{1,2 *}$; J. A. Conceiçãõo ${ }^{1,3} ;$ M. L. S. Rosa ${ }^{1,2}$; H. Conceição ${ }^{1,2,3}$ \\ ${ }^{1}$ Laboratório de Petrologia Aplicada à Pesquisa Mineral, Universidade Federal de Sergipe, 49100-000, São \\ Cristóvão, Sergipe, Brasil \\ ${ }^{2}$ Programa de Pós-Graduação em Geociências e Análise de Bacias, Complexo Laboratorial Multiusuários da \\ Universidade Federal de Sergipe, Prédio das Geociências, 49100-000, São Cristóvão, Sergipe, Brasil \\ ${ }^{3}$ Programa de Pós-Graduação em Geologia, Universidade Federal da Bahia, 40170-020, Salvador, Bahia, Brasil
}

*fspereira@academico.ufs.br

(Recebido em 24 de maio de 2017; aceito em 01 de agosto de 2017)

Corpos leucograníticos relacionados ao Ciclo Brasiliano apresentam ampla distribuição no Sistema Orogênico Sergipano, localizado no setor extremo sul da Província Borborema. O Stock Lagoa de Dentro (SLD) é um representante desse magmatismo, que intrude as rochas metassupracrustais do Domínio Macururé, na porção centro-norte do estado de Sergipe. Trata-se de uma intrusão com cerca de $13 \mathrm{~km}^{2} \mathrm{de}$ área aflorante, constituída por monzogranitos e álcali-feldspato granitos à duas micas. Neste artigo são apresentados e discutidos dados químicos dos principais minerais identificados nas rochas do SLD. Os feldspatos são homogêneos em composição e geralmente ocorrem como fases puras de ortoclásio ( $\left.\mathrm{Or}_{92-97}\right)$ e albita $\left(\mathrm{An}_{1-7}\right)$. A mica dioctaédrica possui composição intermediária entre muscovita e celadonita, dada pela substituição de ${ }^{\mathrm{VI}} \mathrm{Al}$ por $\mathrm{Fe}+\mathrm{Mg}$ nos sítios octaédricos, acompanhada pela substituição de ${ }^{\mathrm{IV}} \mathrm{Al}$ por $\mathrm{Si}$ nas posições tetraédricas. A biotita é ferrosa e mostra sinais de reequilíbrio, refletindo variados graus de cloritização e oxidação observados nos estudos petrográficos. Em diagramas de associações magmáticas, a biotita exibe afinidade com as suítes graníticas peraluminosas e caráter transicional entre as séries CálcioAlcalina e Alumino-Potássica. O epídoto $\left(\mathrm{Ps}_{18-24}\right)$ é aluminoso e ocorre como um mineral primário, cristalizado precocemente, e como produto de alteração hidrotermal de plagioclásio. A apatita corresponde a fluorapatita $\left(\mathrm{FAp}_{51-82}\right)$ e o zircão possui assinatura de granitos anatéticos, derivados de fontes crustais ( $\mathrm{Zr} / \mathrm{Hf} \sim 30)$. As composições da ilmenita mostram-se enriquecidas nas moléculas de pirofanita $\left(\mathrm{Php}_{3-14}\right)$ e ecandrewsita $\left(\mathrm{Ec}_{1-20}\right)$ e sugerem que o SLD se cristalizou a partir de um magma com baixa fugacidade de oxigênio.

Palavras-chave: Stock Lagoa de Dentro, Granito, Química Mineral

Leucogranitic bodies related to the Brasiliano Cycle show wide distribution in the Sergipano Orogenic System, located in the extreme southern sector of the Borborema Province. The Lagoa de Dentro Stock (LDS) is a representative of this magmatism, which intrudes the metassupracrust rocks of the Macururé Domain, in the central-northern sector of the Sergipe state. This intrusion comprises about $13 \mathrm{~km}^{2}$ of outcropping area and it is constituted of two micas monzogranites and alkali-feldspar granites. In this paper, are presented and discussed chemical data for the main minerals identified in the LDS rocks. Feldspars has homogeneous composition and generally occur as pure phases of orthoclase ( $\left.\mathrm{Or}_{92-97}\right)$ and albite $\left(\mathrm{An}_{1-7}\right)$. The dioctahedral mica has intermediate composition between muscovite and celadonite, given by the substitution of ${ }^{\mathrm{VI}} \mathrm{Al}$ for $\mathrm{Fe}+\mathrm{Mg}$ in the octahedral sites, followed by the substitution of ${ }^{\mathrm{IV}} \mathrm{Al}$ for $\mathrm{Si}$ in the tetrahedral positions. The biotite is ferrous and shows signals of rebalancing, reflecting varying degrees of chloritization and oxidation observed in petrographic studies. In diagrams of magmatic associations, biotite shows affinity with the peraluminous granitic suites and transitional character between the Calc-Alkaline and Aluminum-Potassic series. The epidote $\left(\mathrm{Ps}_{18-24}\right)$ is aluminous and occurs as a primary mineral crystallized early and as a product of hydrothermal alteration of plagioclase. The apatite corresponds to fluorapatite $\left(\mathrm{FAp}_{51-82}\right)$ and the zircon has signature of anatetic granites, derived from crustal sources $(\mathrm{Zr} / \mathrm{Hf} \sim 30)$. The ilmenite compositions are enriched in the pyrophanite $\left(\mathrm{Php}_{3-14}\right)$ and ecandrewsite $\left(\mathrm{Ec}_{1-20}\right)$ molecules and suggest that the LDS was crystallized from a magma with low oxygen fugacity.

Keywords: Lagoa de Dentro Stock, Granite, Mineral Chemistry 


\section{INTRODUÇÃO}

O Sistema Orogênico Sergipano [1] resultou da colisão entre o Cráton de São Francisco e o Maciço Pernambuco-Alagoas [2] durante o Ciclo Brasiliano. Esse orógeno localiza-se no setor extremo sudeste da Província Borborema (Figura 1A) e é constituído por seis domínios geológicos (Estância, Vaza-Barris, Macururé, Marancó, Poço Redondo e Canindé) com histórias de sedimentação e evoluções tectônicas distintas, separados entre si por zonas de cisalhamento [3] (Figura 1B).

O Domínio Macururé, onde localiza-se o objeto desta pesquisa, é interpretado como uma cunha turbidítica com mais de $13 \mathrm{~km}$ de espessura [4], constituída por uma sequência essencialmente pelítica, com mármores, quartzitos, rochas vulcânicas e calciossilicáticas subordinados. O limite entre os domínios Macururé e Vaza-Barris é feito pela Zona de Cisalhamento São Miguel do Aleixo, a partir do qual ocorre um expressivo volume de granitos e corpos máficos a ultramáficos [5]. No Domínio Macururé, as rochas ígneas plutônicas perfazem cerca de $25 \%$ da sua área [3] e provocam metamorfismo de contato nas encaixantes metassedimentares que chega a atingir a Fácies Hornblenda Hornfels [1].

A granitogênese no Domínio Macururé já foi alvo de vários trabalhos de cunho regional $[6,7$, $8,9,10]$, no entanto, ainda são escassos estudos de detalhe sobre a química das fases minerais essenciais e acessórias, o que dificulta a realização de inferências acerca dos parâmetros intensivos atuantes no momento da colocação desses corpos e sobre a natureza dos magmas progenitores desses granitos.

Neste artigo são apresentados e discutidos os resultados das análises químicas pontuais realizadas nas principais fases minerais presentes nas rochas que compõem o Stock Lagoa de Dentro (SLD), um dos representantes do magmatismo leucogranítico do Domínio Macururé, cuja gênese é, em parte, atribuída à fusão parcial dos metassedimentos encaixantes [1, 11, 12].

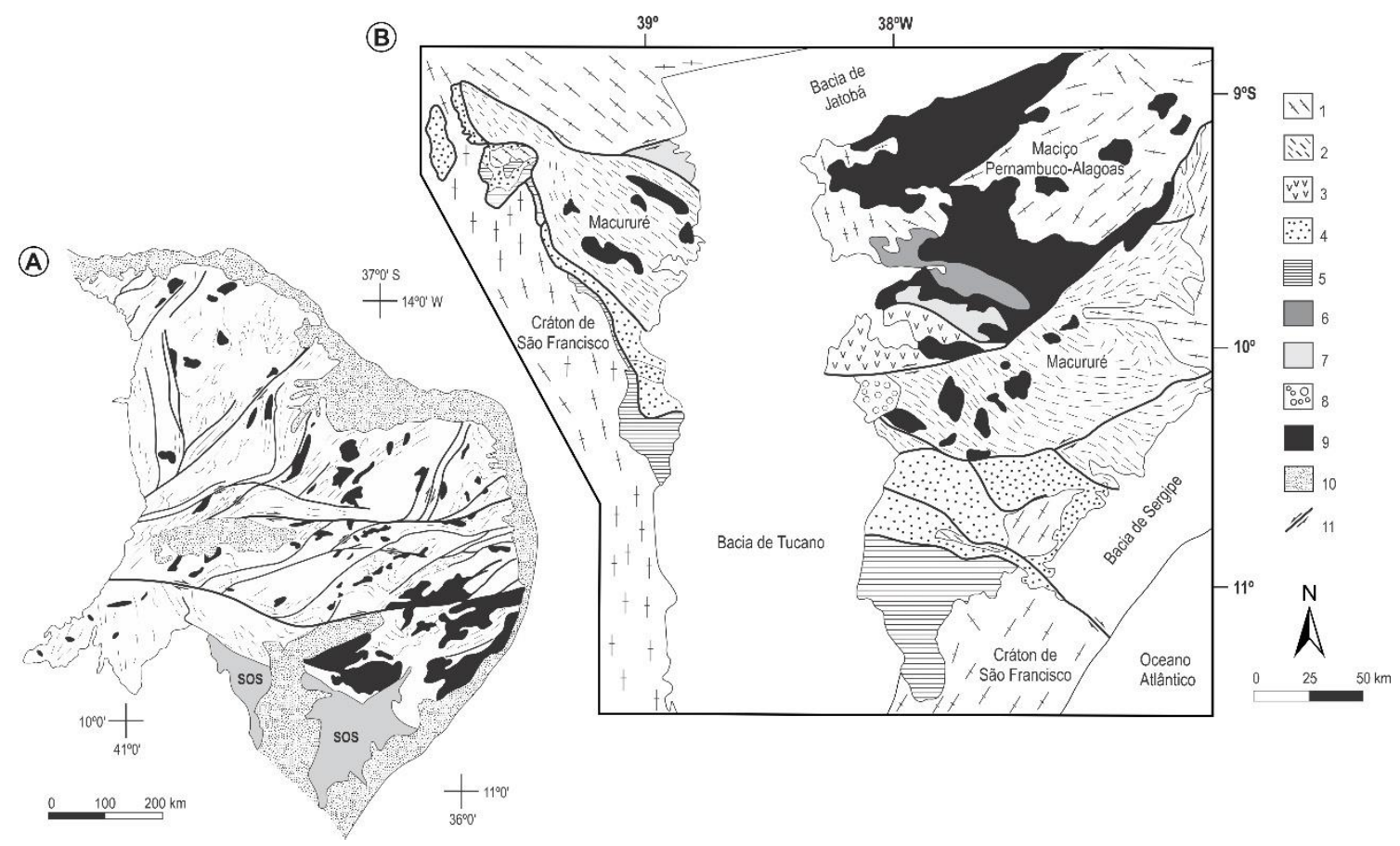

Figura 1. Localização do Sistema Orogênico Sergipano. (A) Mapa simplificado da geologia do nordeste do Brasil, com destaque para o Sistema Orogênico Sergipano (SOS) ao sul da Província Borborema. (B) Sistema Orogênico Sergipano [1]. 1: gnaisses de alto grau, 2: Domínio Macururé, 3: Domínio Marancó, 4: Domínio Vaza-Barris, 5: Domínio Estância, 6: Domínio Canindé, 7: Domínio Poço Redondo, 8: Graben Juá, 9: plútons brasilianos, 10: cobertura sedimentar, 11: zonas de cisalhamento. 


\section{ASPECTOS GERAIS DO STOCK LAGOA DE DENTRO}

O Stock Lagoa de Dentro localiza-se entre os municípios de Gracho Cardoso e Cumbe, na porção centro-norte do Estado de Sergipe. Este corpo aflora em uma área de $13 \mathrm{~km}^{2}$, possui geometria aproximadamente elíptica e eixo maior orientado na direção N-S. Os contatos do stock são feitos com os metassedimentos mesoproterozoicos de baixo grau do Domínio Macururé (Figura 2).

(A)

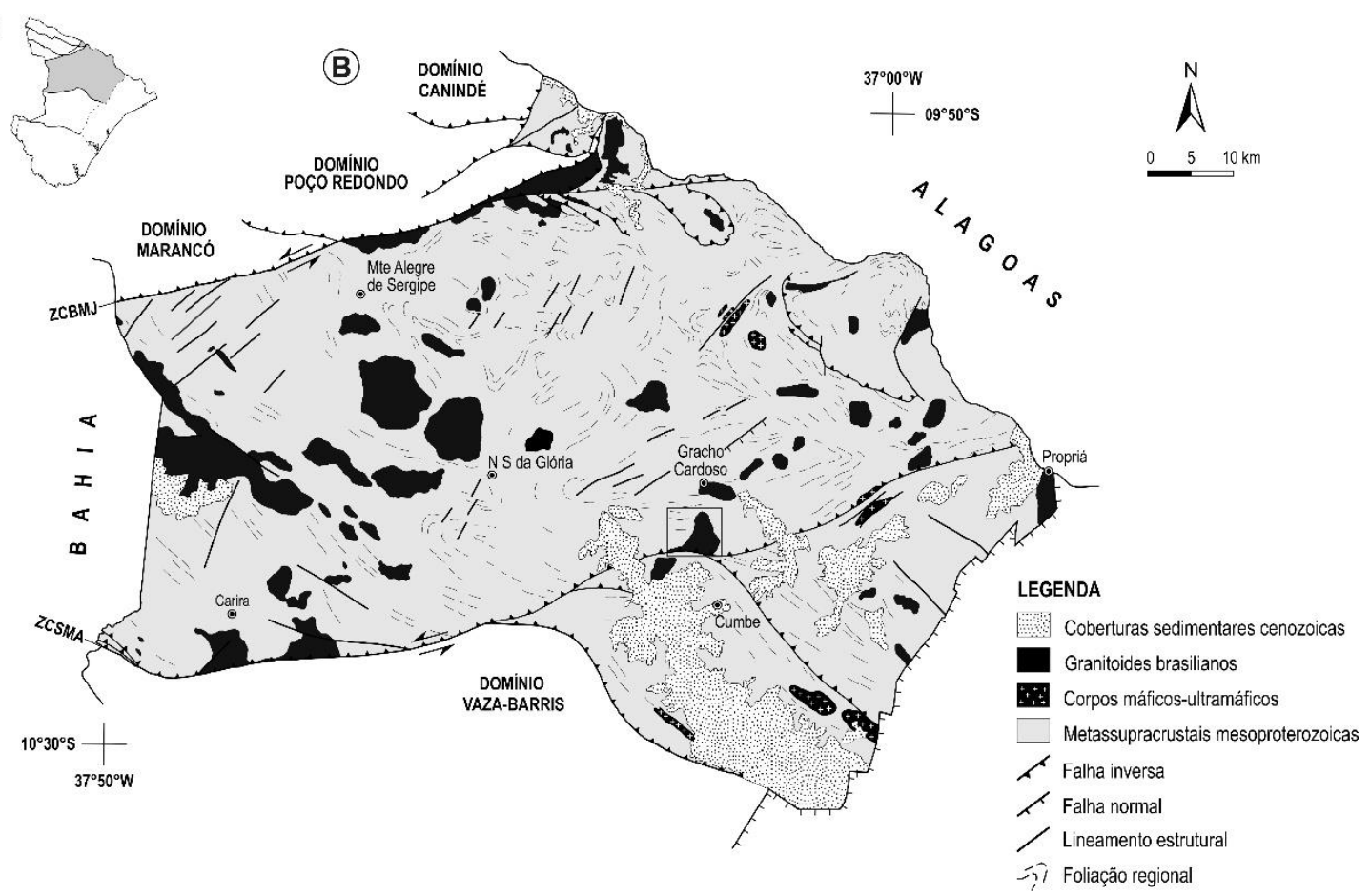

Figura 2. (A) Contorno do Estado de Sergipe, com destaque em cinza para o Domínio Macururé. (B) Esboço geológico do Domínio Macururé em Sergipe, mostrando a distribuição dos corpos plutônicos [13]. Os contatos com os domínios adjacentes são definidos pelas zonas de cisalhamento de São Miguel do Aleixo (ZCSMA) e Belo Monte-Jeremoabo (ZCBMJ). A região delimitada pelo retângulo preto corresponde à área aflorante do Stock Lagoa de Dentro.

Em campo, as rochas do SLD exibem grande homogeneidade composicional e textural. Estas correspondem a granitos cinzas e róseos, cujas principais diferenças entre os afloramentos visitados se devem às variações nos conteúdos de biotita e muscovita. Esses granitos são equigranulares, possuem granulação média e apresentam textura de fluxo magmático bem preservada, materializada pela orientação de cristais de micas paralelamente à foliação das encaixantes.

De acordo com o esquema de nomenclatura modal recomendada pela International Union of Geological Sciences [14], as rochas do SLD são hololeucocráticas (M'=2,4-8,2\%) e possuem composição monzogranítica a álcali-feldspato granítica (Figura 3). Os tipos petrográficos identificados compreendem muscovita álcali-feldspato granito, muscovita monzogranito e monzogranito [15]. A mineralogia essencial dessas rochas é constituída por quartzo (34,3-40,3\% em volume [vol.]), albita $(27,0-31,0 \%$ vol.) e microclina $(19,0-27,0 \%$ vol.). Muscovita $(4,35-8,3 \%$ vol.), biotita (0,5-4,9\% vol.) e epídoto (0,1-1,5\% vol.) geralmente ocorrem como minerais varietais, enquanto apatita, zircão, rutilo e ilmenita são os acessórios $(<0,1 \%$ vol.). As fases secundárias identificadas foram clorita, calcita, sericita, epídoto e titanita.

Os dados geoquímicos revelam os granitos do SLD são evoluídos $\left(\mathrm{SiO}_{2}>67,8 \%\right)$, potássicos $\left(1,1<\mathrm{K}_{2} \mathrm{O} / \mathrm{Na}_{2} \mathrm{O}<1,3\right)$, magnesianos a ferrosos e peraluminosos $(1,07<\mathrm{A} / \mathrm{CNK}<1,32)$, que apresentam afinidade com as rochas das séries Cálcio-Alcalina de Alto K e Shoshonítica. Os baixos conteúdos de alguns elementos traços, a exemplo de $\mathrm{Nb}$ (2,0-2,2 ppm), Ta (0,1-0,3 ppm) 
e Y (1,9-4,5 ppm) são característicos de magmas orogênicos, o que é compatível com o ambiente colisional de arco atribuído para a colocação dos granitos do Sistema Orogênico Sergipano [12].



Figura 3. Diagramas $Q A P$ e $Q(A+P) M$ ' para classificação modal de rochas ígneas plutônicas [14], aplicados às amostras do Stock Lagoa de Dentro. $Q=$ quartzo, $A=$ feldspato alcalino + albita $(A n<5 \%)$, $P=$ plagioclásio $(A n>5 \%), M^{\prime}=$ minerais máficos.

\section{MATERIAL E MÉTODOS}

A investigação sobre a mineralogia dos granitos do SLD foi realizada a partir do estudo de quatro lâminas delgado-polidas de amostras representativas. Essas lâminas foram analisadas inicialmente com microscópio petrográfico de luz transmitida e refletida da marca OPTON (TNP-09T), nas dependências do Laboratório de Microscopia e Lupas do Departamento de Geologia da Universidade Federal de Sergipe.

A localização e análise dos cristais estudados foram executadas com o microscópio eletrônico de varredura (MEV) da marca Tescan-Vega 3, do Laboratório de Microanálises do Condomínio de Laboratórios Multiusuários das Geociências, na Universidade Federal de Sergipe. As amostras foram metalizadas com carbono, utilizando-se um equipamento de metalização Quorum ${ }^{\circledR}$, modelo Q150R ES. A determinação das composições químicas pontuais foi realizada por meio de um espectrômetro de energia dispersiva (EDS) X-Act da Oxford Instruments e as imagens eletrônicas foram obtidas a partir de detectores de sinais de elétrons secundários e elétrons retroespalhados. O EDS foi calibrado com a energia do $\mathrm{Cu}$ e a aferição dos resultados obtidos foi feita utilizandose padrões internacionais ASTIMEX $^{\circledR}$ em silicatos (e.g. biotita, muscovita, zircão, albita e oligoclásio) e óxidos (magnetita e ilmenita). O erro das determinações situou-se entre 5\% e 8\% para os elementos químicos com conteúdos superiores a $6 \%$ em peso. As condições analíticas adotadas nesse estudo foram tensão elétrica de $15 \mathrm{kV}$ e intensidade de corrente variando de $15 \mathrm{a}$ $20 \mathrm{nA}$, que gera um feixe de elétrons com diâmetro compreendido entre 280 e $830 \mathrm{~nm}$.

\section{RESULTADOS E DISCUSSÃO}

Neste trabalho são apresentados e discutidos dados petrográficos/texturais e as composições químicas pontuais de cristais de plagioclásio, feldspato alcalino, muscovita, biotita, epídoto, apatita, zircão e ilmenita do Stock Lagoa de Dentro. O conjunto completo de análises mineraloquímicas pode ser obtido pelos interessados mediante pedidos ao e-mail do primeiro autor. 


\subsection{Feldspatos}

Foram identificados no SLD feldspato alcalino e plagioclásio. O primeiro ocorre anédrico e com geminação bem desenvolvida em padrão tartan segundo as leis Albita-Periclina, típicos de cristais de microclina. $\mathrm{O}$ seu aspecto é normalmente límpido, exibem fraca extinção ondulante e as inclusões mais comuns são cristais de albita e muscovita.

O plagioclásio ocorre como cristais anédricos a subédricos, em sua maioria geminados segundo as leis Albita e Albita-Carlsbad, com planos de composição localmente vergados e descontínuos. Exibe extinção ondulante concêntrica de intensidade fraca a moderada e incluem cristais de microclina, muscovita, epídoto, apatita e zircão. Alguns cristais mostram zonação normal, com núcleos mais alterados (para sericita, epídoto e carbonato) que as bordas.

As fórmulas estruturais dos feldspatos foram calculadas com base de 32 oxigênios, considerando a formula geral $\mathrm{XZ}_{4} \mathrm{O}_{8}[16]$. Resultados representativos das análises químicas nos cristais de feldspatos estão listados na tabela 1.

Tabela 1. Análises químicas representativas de cristais de feldspato. MAFG: Muscovita Álcali-Feldspato Granito, MMG: Muscovita Monzogranito, MG: Monzogranito.

\begin{tabular}{|c|c|c|c|c|c|c|c|c|c|c|c|c|c|}
\hline \multirow{2}{*}{$\begin{array}{l}\text { Amostra } \\
\text { Rocha } \\
\mathrm{SiO}_{2}\end{array}$} & \multicolumn{3}{|c|}{$\begin{array}{c}\text { FDS-588 } \\
\text { MAFG }\end{array}$} & \multicolumn{4}{|c|}{$\begin{array}{c}\text { FDS-589 } \\
\text { MMG }\end{array}$} & \multicolumn{4}{|c|}{$\begin{array}{c}\text { FDS-590 } \\
\text { MAFG }\end{array}$} & \multicolumn{2}{|c|}{$\begin{array}{c}\text { FDS-592 } \\
\text { MG }\end{array}$} \\
\hline & 67,7 & 64,6 & 64,4 & 66,7 & 66,7 & 68,1 & 65,0 & 68,5 & 68,4 & 64,6 & 64,7 & 67,8 & 64,3 \\
\hline $\mathrm{Al}_{2} \mathrm{O}_{3}$ & 20,0 & 18,8 & 19,0 & 20,9 & 20,7 & 20,1 & 18,7 & 19,6 & 19,9 & 18,9 & 18,8 & 20,2 & 18,7 \\
\hline $\mathrm{K}_{2} \mathrm{O}$ & & 15,8 & 15,7 & & & & 15,7 & 0,4 & & 15,9 & 15,9 & & 16,2 \\
\hline $\mathrm{Na}_{2} \mathrm{O}$ & 11,5 & 0,7 & 0,4 & 11,0 & 11,1 & 11,8 & 0,6 & 11,5 & 11,8 & 0,6 & 0,6 & 11,5 & 0,7 \\
\hline $\mathrm{CaO}$ & 0,8 & & & 1,4 & 1,5 & & & & & & & 0,5 & \\
\hline $\mathrm{BaO}$ & & & 0,6 & & & & & & & & & & \\
\hline Total & 100,0 & 99,9 & 100,1 & 100,0 & 100,0 & 100,0 & 100,0 & 100,0 & 100,1 & 100,0 & 100,0 & 100,0 & 99,9 \\
\hline $\mathrm{Si}$ & 11,854 & 11,936 & 11,910 & 11,695 & 11,704 & 11,897 & 11,978 & 11,975 & 11,933 & 11,926 & 11,943 & 11,856 & 11,916 \\
\hline $\mathrm{Al}$ & 4,127 & 4,094 & 4,141 & 4,319 & 4,281 & 4,138 & 4,061 & 4,038 & 4,092 & 4,112 & 4,090 & 4,163 & 4,084 \\
\hline [Z] & 15,981 & 16,030 & 16,052 & 16,013 & 15,985 & 16,035 & 16,039 & 16,013 & 16,025 & 16,038 & 16,033 & 16,019 & 16,001 \\
\hline K & & 3,724 & 3,704 & & & & 3,691 & 0,089 & & 3,745 & 3,744 & & 3,830 \\
\hline $\mathrm{Na}$ & 3,904 & 0,251 & 0,143 & 3,739 & 3,776 & 3,997 & 0,214 & 3,898 & 3,991 & 0,215 & 0,215 & 3,899 & 0,252 \\
\hline $\mathrm{Ca}$ & 0,150 & & & 0,263 & 0,282 & & & & & & & 0,094 & \\
\hline $\mathrm{Ba}$ & & & 0,043 & & & & & & & & & & \\
\hline$[\mathbf{X}]$ & 4,054 & 3,975 & 3,891 & 4,002 & 4,058 & 3,997 & 3,905 & 3,987 & 3,991 & 3,959 & 3,959 & 3,993 & 4,082 \\
\hline $\mathrm{Ab}$ & 96,3 & 6,3 & 3,7 & 93,4 & 93,1 & 100,0 & 5,5 & 97,8 & 100,0 & 5,4 & 5,4 & 97,7 & 6,2 \\
\hline Or & & 93,7 & 95,2 & & & & 94,5 & 2,2 & & 94,6 & 94,6 & & 93,8 \\
\hline An & 3,7 & & & 6,6 & 6,9 & & & & & & & 2,3 & \\
\hline Cs & & & 1,1 & & & & & & & & & & \\
\hline
\end{tabular}

A composição dos cristais de feldspato analisados é apresentada na figura 4 em termos dos componentes Albita [ $\left.\mathrm{NaAlSi}_{3} \mathrm{O}_{8}\right]$, Ortoclásio [ $\left.\mathrm{KAlSi}_{3} \mathrm{O}_{8}\right]$ e Anortita $\left[\mathrm{CaAl}_{2} \mathrm{Si}_{2} \mathrm{O}_{6}\right]$.



Figura 4. Sistema ternário Albita-Ortoclásio-Anortita para classificação dos cristais de feldspatos. 
Os cristais de plagioclásio do SLD possuem composição albítica e apresentam grande homogeneidade composicional, ocorrendo como fases puras ou com concentrações da molécula de anortita entre 1,3 e 6,9\%, refletindo o caráter evoluído das rochas estudadas.

Os cristais de feldspato alcalino também pouco variam sua composição, situando-se no intervalo entre $\mathrm{Or}_{92} \mathrm{Ab}_{8} \mathrm{An}_{0}$ e $\mathrm{Or}_{97} \mathrm{Ab}_{3} \mathrm{An}_{0}$. Nos cristais em que é observada a ocorrência de bário, os teores da molécula de Celsiana $\left[\mathrm{BaAl}_{2} \mathrm{Si}_{2} \mathrm{O}_{8}\right]$ variam entre 1,1 e $1,5 \%$.

\subsection{Micas}

Muscovita e biotita são as fases minerais varietais de maior expressão volumétrica nos granitos do SLD. Estes minerais ocorrem em agregados, juntamente com epídoto primário e, por vezes, com minerais opacos.

A muscovita apresenta-se subédrica a anédrica e, frequentemente, exibe microdobramentos em kink bands. Seus contatos com a maioria dos minerais da lâmina são curvos a reentrantes e retos com albita e clorita. As inclusões observadas são cristais de quartzo, albita, apatita e epídoto.

Os cristais de biotita são euédricos a anédricos, possuem cor marrom e acentuado pleocroísmo, que varia de castanho-claro a castanho-escuro. Os contatos são curvos com a maior parte dos minerais adjacentes e retos com outros cristais de micas. Nos granitos estudados, as microtexturas sugerem que a biotita é primária, no entanto, são observadas evidências de transformações tardimagmáticas ou alterações secundárias, como cloritização e oxidação, sobretudo ao longo dos planos de clivagem. A biotita foi identificada em todas as rochas do SLD, contudo, em três das lâminas analisadas esta apresenta-se completamente substituída por clorita e, por este motivo, seus dados não são considerados nesse estudo.

As fórmulas estruturais dos cristais de micas foram calculadas com base de 22 oxigênios e os sítios foram preenchidos de acordo com a fórmula ideal $\mathrm{X}_{2} \mathrm{Y}_{4-6} \mathrm{Z}_{8} \mathrm{O}_{20} \mathrm{~W}_{4}$ [16], assumindo-se todo o ferro presente como $\mathrm{Fe}^{2+}$. $\mathrm{O}$ conteúdo de $\mathrm{OH}$ e, consequentemente, de $\mathrm{H}_{2} \mathrm{O}$ foi calculado por estequiometria, considerando a completa ocupação do sítio aniônico $(\mathrm{F}+\mathrm{Cl}+\mathrm{OH}=4$ apfu), conforme recomendações de Tindle \& Webb (1990) [17]. Dados químicos representativos para as micas do SLD são apresentados na tabela 2.

\subsubsection{Muscovita}

De acordo com a classificação de Deer et al. (1992) [16], as micas dioctaédricas do SLD correspondem à muscovita, cujos sítios octaédricos $\mathrm{X}$ e Y são preenchidos, em sua maior parte, por K (1,477-1,960 átomos por fórmula unitária [apfu]) e $\mathrm{Al}$ (2,912-3,342 apfu), respectivamente.

No sistema ternário ${ }^{\mathrm{IV}} \mathrm{Al}-(\mathrm{Fe}+\mathrm{Mg})-{ }^{\mathrm{VI}} \mathrm{Al}$ [18] para classificação de micas potássicas, os cristais analisados mostram significativa contribuição da molécula celadonítica, afastando-se do polo composicional da muscovita e descrevendo um trend de enriquecimento em Fe e Mg (Figura 5).
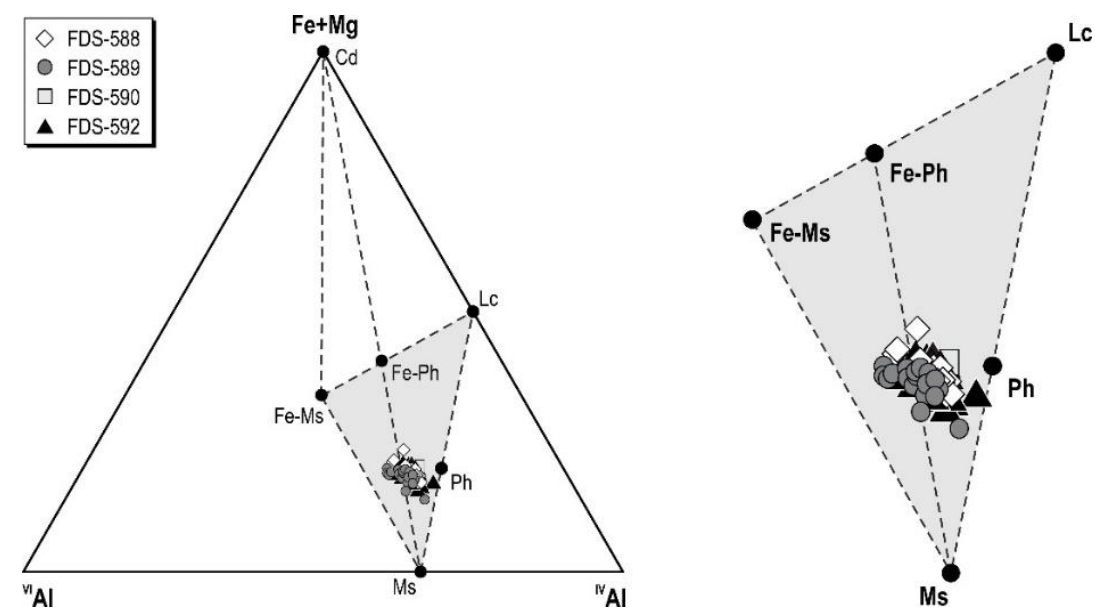

Figura 5. Projeção ${ }^{I V} \mathrm{Al}-(\mathrm{Fe}+\mathrm{Mg})-{ }^{V I} \mathrm{Al}$ para classificação de micas potássicas dioctaédricas [18], onde são representados os polos composicionais da Muscovita (Ms), Muscovita Ferrosa (Fe-Ms), Celadonita (Cd), Leucofilita (Lc), Fengita (Ph) e Fengita Ferrosa (Fe-Ph). 
Tabela 2. Análises químicas representativas de cristais de muscovita (Ms) e biotita (Bt). MAFG: Muscovita Álcali-Feldspato Granito, MMG: Muscovita Monzogranito, MG: Monzogranito.

\begin{tabular}{|c|c|c|c|c|c|c|c|c|c|c|c|c|c|}
\hline \multirow{2}{*}{$\begin{array}{l}\text { Amostra } \\
\text { Rocha } \\
\text { Mineral }\end{array}$} & \multicolumn{2}{|c|}{$\begin{array}{c}\text { FDS-588 } \\
\text { MAFG }\end{array}$} & \multicolumn{7}{|c|}{$\begin{array}{c}\text { FDS-589 } \\
\text { MMG }\end{array}$} & \multicolumn{2}{|c|}{$\begin{array}{c}\text { FDS-590 } \\
\text { MAFG }\end{array}$} & \multicolumn{2}{|c|}{$\begin{array}{c}\text { FDS-592 } \\
\text { MG }\end{array}$} \\
\hline & Ms & Ms & Ms & Ms & Bt & Bt & Bt & Bt & Bt & Ms & Ms & Ms & Ms \\
\hline $\mathrm{SiO}_{2}$ & 48,6 & 48,6 & 48,4 & 48,2 & 39,6 & 39,6 & 40,1 & 38,6 & 38,8 & 48,5 & 48,7 & 48,8 & 48,2 \\
\hline $\mathrm{TiO}_{2}$ & 0,1 & 0,3 & 0,2 & 0,1 & 1,1 & 1,2 & 1,3 & 1,0 & 0,8 & & 1,2 & 0,8 & 0,4 \\
\hline $\mathrm{Al}_{2} \mathrm{O}_{3}$ & 28,4 & 27,9 & 28,3 & 28,3 & 18,2 & 16,2 & 17,3 & 17,6 & 17,1 & 28,4 & 27,6 & 28,2 & 27,6 \\
\hline $\mathrm{FeO}$ & 4,5 & 4,7 & 5,3 & 4,9 & 23,0 & 22,4 & 21,1 & 22,1 & 22,8 & 4,7 & 4,4 & 4,2 & 5,1 \\
\hline $\mathrm{MnO}$ & 0,2 & 0,1 & & & 0,1 & 0,2 & 0,2 & 0,4 & 0,2 & & & & \\
\hline $\mathrm{MgO}$ & 2,3 & 2,4 & 2,2 & 2,3 & 6,8 & 7,6 & 7,2 & 7,5 & 7,4 & 2,2 & 2,0 & 2,2 & 2,5 \\
\hline $\mathrm{Na}_{2} \mathrm{O}$ & 0,4 & 0,2 & 0,2 & 0,3 & 0,3 & 0,2 & 0,3 & 0,4 & 0,3 & & 0,5 & 0,4 & 0,4 \\
\hline $\mathrm{K}_{2} \mathrm{O}$ & 10,6 & 10,9 & 10,5 & 10,9 & 6,9 & 8,5 & 8,4 & 8,2 & 8,3 & 11,3 & 10,6 & 10,5 & 10,9 \\
\hline $\mathrm{F}$ & 0,4 & 0,4 & 0,8 & 0,7 & & & & 0,4 & 0,5 & & & 0,4 & 0,3 \\
\hline $\mathrm{Cl}$ & 0,1 & & 0,1 & & & & & & & & & 0,1 & 0,1 \\
\hline $\mathrm{H}_{2} \mathrm{O}$ & 4,2 & 4,2 & 4,0 & 4,1 & 4,0 & 4,0 & 4,0 & 3,8 & 3,7 & 4,4 & 4,4 & 4,2 & 4,2 \\
\hline Subtotal & 99,7 & 99,6 & 99,9 & 99,8 & 100,0 & 100,0 & 100,0 & 99,8 & 99,8 & 99,4 & 99,4 & 99,7 & 99,6 \\
\hline $\mathrm{O}=\mathrm{F}, \mathrm{Cl}$ & 0,191 & 0,168 & 0,359 & 0,295 & & & & 0,168 & 0,211 & & & 0,191 & 0,149 \\
\hline Total & 99,5 & 99,4 & 99,5 & 99,5 & 100,0 & 100,0 & 100,0 & 99,6 & 99,6 & 99,4 & 99,4 & 99,5 & 99,5 \\
\hline $\mathrm{Si}$ & 6,602 & 6,609 & 6,589 & 6,571 & 5,914 & 5,988 & 6,003 & 5,847 & 5,894 & 6,601 & 6,618 & 6,610 & 6,587 \\
\hline${ }^{\mathrm{IV}} \mathrm{Al}$ & 1,398 & 1,391 & 1,411 & 1,429 & 2,086 & 2,012 & 1,997 & 2,153 & 2,106 & 1,399 & 1,382 & 1,390 & 1,413 \\
\hline$[\mathbf{Z}]$ & 8,000 & 8,000 & 8,000 & 8,000 & 8,000 & 8,000 & 8,000 & 8,000 & 8,000 & 8,000 & 8,000 & 8,000 & 8,000 \\
\hline${ }^{\mathrm{V}} \mathrm{A} \mathrm{Al}$ & 3,143 & 3,094 & 3,124 & 3,117 & 1,128 & 0,876 & 1,050 & 0,984 & 0,955 & 3,160 & 3,031 & 3,108 & 3,030 \\
\hline $\mathrm{Ti}$ & 0,010 & 0,029 & 0,020 & 0,010 & 0,119 & 0,142 & 0,151 & 0,109 & 0,088 & & 0,127 & 0,078 & 0,039 \\
\hline $\mathrm{Fe}$ & 0,510 & 0,532 & 0,598 & 0,565 & 2,881 & 2,825 & 2,642 & 2,798 & 2,904 & 0,534 & 0,500 & 0,476 & 0,578 \\
\hline $\mathrm{Mn}$ & 0,022 & 0,011 & & & 0,012 & 0,025 & 0,024 & 0,049 & 0,025 & & & & \\
\hline $\mathrm{Mg}$ & 0,464 & 0,484 & 0,446 & 0,465 & 1,519 & 1,707 & 1,606 & 1,691 & 1,675 & 0,446 & 0,407 & 0,444 & 0,506 \\
\hline$[\mathbf{Y}]$ & 4,149 & 4,150 & 4,187 & 4,156 & 5,659 & 5,575 & 5,474 & 5,631 & 5,645 & 4,140 & 4,065 & 4,105 & 4,153 \\
\hline $\mathrm{Na}$ & 0,101 & 0,050 & 0,050 & 0,076 & 0,083 & 0,056 & 0,084 & 0,113 & 0,085 & & 0,126 & 0,100 & 0,101 \\
\hline K & 1,837 & 1,888 & 1,824 & 1,905 & 1,318 & 1,646 & 1,612 & 1,577 & 1,600 & 1,960 & 1,841 & 1,815 & 1,897 \\
\hline$[\mathbf{X}]$ & 1,938 & 1,938 & 1,874 & 1,980 & 1,402 & 1,702 & 1,696 & 1,690 & 1,685 & 1,960 & 1,967 & 1,915 & 1,998 \\
\hline $\mathrm{F}$ & 0,172 & 0,172 & 0,344 & 0,302 & & & & 0,192 & 0,240 & & & 0,171 & 0,130 \\
\hline $\mathrm{Cl}$ & 0,023 & & 0,023 & & & & & & & & & 0,023 & 0,023 \\
\hline $\mathrm{OH}$ & 3,805 & 3,828 & 3,633 & 3,698 & 4,000 & 4,000 & 4,000 & 3,808 & 3,760 & 4,000 & 4,000 & 3,806 & 3,847 \\
\hline [W] & 4,000 & 4,000 & 4,000 & 4,000 & 4,000 & 4,000 & 4,000 & 4,000 & 4,000 & 4,000 & 4,000 & 4,000 & 4,000 \\
\hline $\mathrm{Al}^{\mathrm{T}}$ & 4,541 & 4,485 & 4,535 & 4,546 & 3,215 & 2,888 & 3,047 & 3,137 & 3,061 & 4,558 & 4,413 & 4,498 & 4,443 \\
\hline $\mathrm{Fe} / \mathrm{Fe}+\mathrm{Mg}$ & 0,52 & 0,52 & 0,57 & 0,54 & 0,65 & 0,62 & 0,62 & 0,62 & 0,63 & 0,54 & 0,55 & 0,51 & 0,53 \\
\hline ISA & 2,34 & 2,31 & 2,42 & 2,30 & 2,29 & 1,70 & 1,80 & 1,86 & 1,82 & 2,33 & 2,24 & 2,35 & 2,22 \\
\hline
\end{tabular}

Os diagramas de variação apresentados na figura 6 demonstram que o desvio da composição ideal apresentado pelos cristais de muscovita do SLD se deve à substituição de $\mathrm{Al}$ por Si no sítio tetraédrico $\left(\mathrm{R}^{2}=1,00\right)$ e de $\mathrm{Al}$ por $\mathrm{Fe}+\mathrm{Mg}$ na posição octaédrica $\left(\mathrm{R}^{2}=0,58\right)$. Este mecanismo de acomodação catiônica em micas dioctaédricas com estrutura da muscovita é descrito na literatura como substituição fengítica ou tschermaquítica. Segundo Foster (1960) [19] a substituição de um cátion trivalente por um bivalente na camada octaédrica gera uma carga negativa, que é balanceada por um aumento na carga positiva da camada tetraédrica pela substituição de ${ }^{\mathrm{IV}} \mathrm{Al}$ por $\mathrm{Si}$, conforme a equação $\mathrm{M}^{2+}+\mathrm{Si}^{4+} \rightleftarrows{ }^{\mathrm{VI}} \mathrm{Al}^{3+}+{ }^{\mathrm{IV}} \mathrm{Al}^{3+}\left(\mathrm{R}^{2}=0,78\right)$.

No diagrama ternário utilizado para distinção entre muscovita primária e secundária [20], os baixos conteúdos de $\mathrm{Ti}(0,010-0,138 \mathrm{apfu})$ e $\mathrm{Na}(0,025-0,175 \mathrm{apfu})$ comparativamente ao $\mathrm{Mg}$ $(0,365-0,580 \mathrm{apfu})$ projetam a maioria dos cristais de mica dioctaédrica no campo da muscovita secundária, refletindo reequilíbrio em fase magmática tardia ou em estágio subsolidus (Figura 7A). Essa observação adiciona-se a favor de dados experimentais [21] que demonstram um aumento da substituição fengítica com temperaturas decrescentes. No sistema ternário $\mathrm{M}^{2+}$-Al-Si [21] com isotermas calculadas para o sistema ferroso, as amostras analisadas apresentam ampla substituição em direção ao polo composicional da fengita e indicam temperaturas de reequilíbrio inferiores a $400{ }^{\circ} \mathrm{C}$ (Figura 7B). 



Figura 6. Diagramas de correlação catiônica em apfu para a mica dioctaédrica do Stock Lagoa de Dentro. Membros ideais muscovita (Ms) e fengita (Ph) conforme Deer et al. (1992) [16].
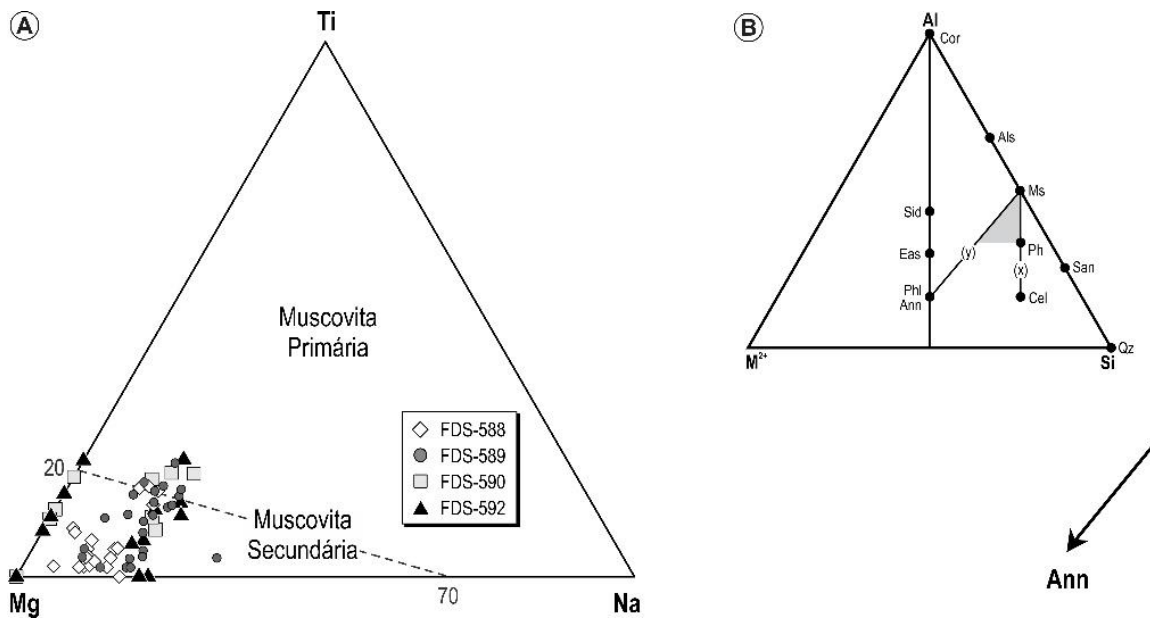

Figura 7. (A) Diagrama Mg-Ti-Na para distinção entre muscovita de origem primária e secundária [20].

(B) Comportamento das micas dioctaédricas do Stock Lagoa de Dentro no sistema ternário $\mathrm{M}^{2+}$-Al-Si, com isotermas de $600{ }^{\circ} \mathrm{C} \mathrm{e} 400{ }^{\circ} \mathrm{C}$ calculadas para o sistema ferroso [21]. Os vetores x e y representam os mecanismos de substituição fengítica e biotítica, respectivamente. Muscovita (Ms), Fengita (Ph),

Celadonita (Cel), Flogopita (Phl), Annita (Ann), Eastonita (Eas), Siderofilita (Sid), Coríndon (Cor), Aluminossilicato (Als), Sanidina (San), Quartzo $(Q z)$.

\subsubsection{Biotita}

Os dados químicos dos cristais de micas trioctaédricas posicionam-se na área das biotitas (Deer et al., 1992) [16]. No quadrilátero Flogopita-Annita-Siderofilita-Eastonita para classificação de biotita [22], as amostras analisadas mostram composições enriquecidas na molécula de annita, com razões Fe/Fe+Mg entre 0,61 e 0,72 (Figura 8A). Resultados semelhantes 
são observados no esquema de classificação de micas trioctaédricas proposto por Foster (1960) [23], onde as amostras analisadas posicionam-se no campo da biotita ferrosa (Figura 8B).

(A)

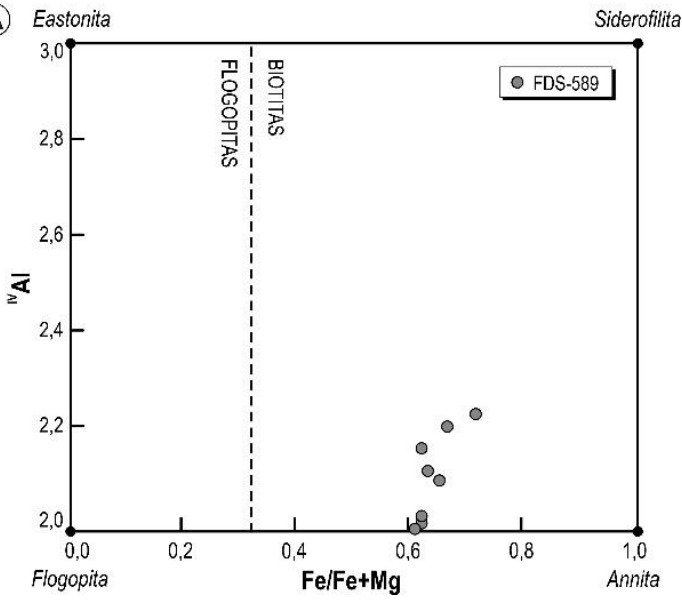



Figura 8. (A) Quadrilátero Flogopita-Annita-Siderofilita-Eastonita para classificação de biotita [22]. (B) Sistema ternário de classificação e nomenclatura de micas trioctaédricas [23].

O sítio Y dos cristais de biotita do SLD possuem teores elevados de $\mathrm{Al}(0,876-1,122$ apfu) e Fe (2,551-3,218 apfu), moderados de Mg (1,202-1,707 apfu) e baixos de Ti (0,064-0,151 apfu). O somatório de cátions nesse sítio revela um défice de carga de 0,097 a 0,526 apfu, que sugere a existência de vacâncias ou indica uma significativa ocupação de Li na posição octaédrica.

A posição W é ocupada por K (1,126-1,646 apfu) e Na (0,056-0,140 apfu). Os baixos totais de cátions nesse sítio (1,238 a 1,702 apfu) podem ser explicados pelo maior grau de hidratação interlamelar da biotita, processo governado pela substituição $(\mathrm{Na}, \mathrm{K}) \rightleftarrows \mathrm{H}_{3} \mathrm{O}^{+}[24]$.

Apreciáveis quantidades de $\mathrm{Al}$ em coordenação octaédrica são comumente observadas em cristais de biotita de granitos peraluminosos, devido a sua coexistência com muscovita e outros minerais ricos em alumínio [25]. Os altos valores do índice de saturação em alumina $[\mathrm{ISA}=\mathrm{Al} /(\mathrm{Ca}+\mathrm{Na}+\mathrm{K})]$ nos cristais de biotita do SLD (Tabela 2) são reflexo dessa característica e evidenciam a alta atividade do alumínio no magma que os originou.

No diagrama $\mathrm{Al}^{\mathrm{T}}$ versus $\mathrm{Mg}$ [26] utilizado para discriminação de associações magmáticas, a biotita exibe composições características de cristais formados a partir de magmas cálcio-alcalinos orogênicos, típicos de zonas de subducção (Figura 9). Apenas uma análise posiciona-se no campo alumino-potássico, na interface com o campo cálcio-alcalino.

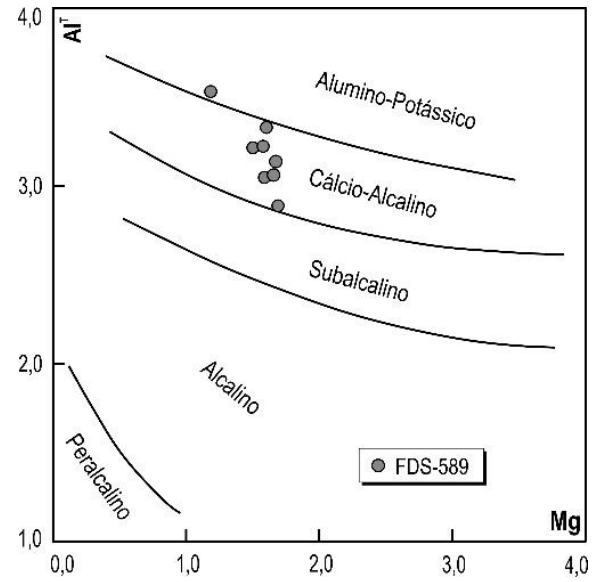

Figura 9. Diagrama Al versus Mg para discriminação de associações magmáticas Alumino-Potássica, Cálcio-Alcalina, Subalcalina, Alcalina e Peralcalina [26], aplicado aos cristais de biotita do Stock Lagoa de Dentro. 
Em diagramas binários que relacionam os conteúdos dos óxidos $\mathrm{FeO} *\left[=\mathrm{FeO}+\left(\mathrm{Fe}_{2} \mathrm{O}_{3} \times 0,899\right)\right]$ $\mathrm{Al}_{2} \mathrm{O}_{3}$ e $\mathrm{MgO}$ [27], as composições dos cristais de biotita do SLD demonstram afinidade com as suítes graníticas peraluminosas (Figura 10), o que está em acordo com os resultados da geoquímica de rocha total [15].


Figura 10. Diagramas para discriminação de séries magmáticas a partir da composição da biotita [27]. Suítes orogênicas cálcio-alcalinas $(C)$, suítes peraluminosas $(P)$, suítes anorogênicas alcalinas $(A)$.

No diagrama utilizado para a distinção entre biotita primária e aquela de natureza secundária [28], as composições dos cristais analisados descrevem um trend verticalizado do campo das biotitas primárias reequilibradas para o das biotitas secundárias (Figura 11), refletindo reequilíbrio magmático tardio.

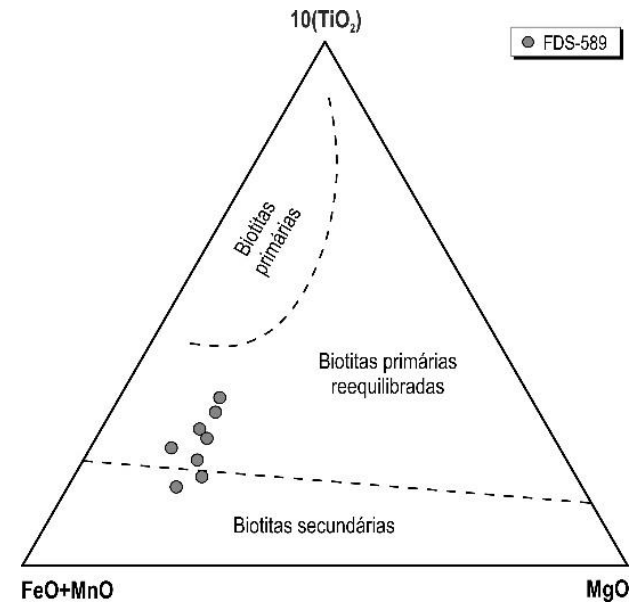

Figura 11. Diagrama discriminante de biotitas primárias, reequilibradas e secundárias [28], aplicado aos cristais de biotita do Stock Lagoa de Dentro.

\subsection{Epídoto}

Os cristais de epídoto do SLD possuem cor verde pálida e exibem discreto pleocroísmo em tons de amarelo-limão a incolor. Duas variedades texturais foram observadas: epídoto primário e secundário. $\mathrm{O}$ primeiro grupo reúne cristais euédricos a subédricos, que ocorrem em íntima associação com muscovita e biotita e apresentam abundantes texturas de reabsorção, como embaiamentos e corrosão parcial das faces cristalinas. Alguns destes cristais exibem pronunciado zoneamento composicional, evidenciado pela mudança das cores de interferência do centro dos cristais para as bordas. Por outro lado, os cristais de epídoto secundário são anédricos, apresentam hábito vermiforme ou granular e limitam-se a ocorrer como produto de alteração do plagioclásio.

Os cálculos da fórmula estrutural do epídoto foram efetuados com base de 25 oxigênios e os sítios foram preenchidos de acordo com a fórmula geral $\mathrm{X}_{2} \mathrm{Y}_{3} \mathrm{Z}_{3}(\mathrm{O}, \mathrm{OH}, \mathrm{F})_{13}$ [16], assumindo todo o ferro como $\mathrm{Fe}^{3+}$. Resultados representativos das análises químicas realizadas nos cristais de epídoto são apresentados na tabela 3 . 
Tabela 3. Análises químicas representativas de cristais de epídoto. MAFG: Muscovita Álcali-Feldspato Granito, MMG: Muscovita Monzogranito, MG: Monzogranito.

\begin{tabular}{lrrrrr|rrrrrrr}
\hline $\begin{array}{l}\text { Amostra } \\
\text { Rocha }\end{array}$ & \multicolumn{3}{c}{$\begin{array}{c}\text { FDS-588 } \\
\text { MAFG }\end{array}$} & \multicolumn{3}{c}{\begin{tabular}{c}
\multicolumn{2}{c}{ FDS-589 } \\
MMG
\end{tabular}} & \multicolumn{7}{c}{ FDS-592 } \\
\hline $\mathrm{SiO}_{2}$ & 40,2 & 40,2 & 38,9 & 39,9 & 39,9 & 40,6 & 39,8 & 40,0 & 39,7 & 39,9 & 39,6 & 39,4 \\
$\mathrm{Al}_{2} \mathrm{O}_{3}$ & 28,2 & 27,9 & 29,3 & 28,2 & 27,2 & 27,7 & 27,0 & 25,9 & 27,0 & 26,5 & 25,8 & 27,8 \\
$\mathrm{FeO}$ & 8,2 & 8,7 & 8,7 & 8,2 & 9,4 & 8,5 & 9,0 & 10,5 & 9,9 & 9,9 & 11,3 & 8,8 \\
$\mathrm{CaO}$ & 23,4 & 23,2 & 23,2 & 23,7 & 23,5 & 23,1 & 24,2 & 23,3 & 23,4 & 23,7 & 23,2 & 24,0 \\
$\mathrm{Na} 2 \mathrm{O}$ & & & & & & & & 0,3 & & & & \\
$\mathrm{Total}$ & 100,0 & 100,0 & 100,1 & 100,0 & 100,0 & 99,9 & 100,0 & 100,0 & 100,0 & 100,0 & 99,9 & 100,0 \\
\hline $\mathrm{Si}$ & 6,068 & 6,073 & 5,881 & 6,033 & 6,051 & 6,130 & 6,047 & 6,090 & 6,029 & 6,065 & 6,042 & 5,981 \\
${ }^{\mathrm{IV}} \mathrm{Al}$ & & & 0,119 & & & & & & & & & 0,019 \\
{$[\mathbf{Z}]$} & $\mathbf{6 , 0 6 8}$ & $\mathbf{6 , 0 7 3}$ & $\mathbf{6 , 0 0 0}$ & $\mathbf{6 , 0 3 3}$ & $\mathbf{6 , 0 5 1}$ & $\mathbf{6 , 1 3 0}$ & $\mathbf{6 , 0 4 7}$ & $\mathbf{6 , 0 9 0}$ & $\mathbf{6 , 0 2 9}$ & $\mathbf{6 , 0 6 5}$ & $\mathbf{6 , 0 4 2}$ & $\mathbf{6 , 0 0 0}$ \\
${ }^{\mathrm{V}} \mathrm{Al}$ & 5,017 & 4,967 & 5,101 & 5,026 & 4,861 & 4,929 & 4,835 & 4,647 & 4,832 & 4,748 & 4,640 & 4,954 \\
$\mathrm{Fe}{ }^{3+}$ & 1,035 & 1,099 & 1,100 & 1,037 & 1,192 & 1,073 & 1,144 & 1,337 & 1,257 & 1,259 & 1,442 & 1,117 \\
{$[\mathbf{Y}]$} & $\mathbf{6 , 0 5 2}$ & $\mathbf{6 , 0 6 6}$ & $\mathbf{6 , 2 0 1}$ & $\mathbf{6 , 0 6 3}$ & $\mathbf{6 , 0 5 4}$ & $\mathbf{6 , 0 0 2}$ & $\mathbf{5 , 9 7 8}$ & $\mathbf{5 , 9 8 4}$ & $\mathbf{6 , 0 9 0}$ & $\mathbf{6 , 0 0 6}$ & $\mathbf{6 , 0 8 2}$ & $\mathbf{6 , 0 7 1}$ \\
$\mathrm{Ca}$ & 3,785 & 3,755 & 3,758 & 3,840 & 3,818 & 3,737 & 3,939 & 3,801 & 3,807 & 3,860 & 3,793 & 3,903 \\
$\mathrm{Na}$ & & & & & & & & 0,089 & & & & \\
{$[\mathbf{X}]$} & $\mathbf{3 , 7 8 5}$ & $\mathbf{3 , 7 5 5}$ & $\mathbf{3 , 7 5 8}$ & $\mathbf{3 , 8 4 0}$ & $\mathbf{3 , 8 1 8}$ & $\mathbf{3 , 7 3 7}$ & $\mathbf{3 , 9 3 9}$ & $\mathbf{3 , 8 8 9}$ & $\mathbf{3 , 8 0 7}$ & $\mathbf{3 , 8 6 0}$ & $\mathbf{3 , 7 9 3}$ & $\mathbf{3 , 9 0 3}$ \\
\hline $\mathrm{Ps}$ & 17 & 18 & 18 & 17 & 20 & 18 & 19 & 22 & 21 & 21 & 24 & 18 \\
\hline
\end{tabular}

A maior parte dos cristais de epídoto analisados classificam-se como epídotos aluminosos [29], caracterizados por apresentarem elevados teores de $\mathrm{Al}$ (4,639-5,471 apfu) relativamente a $\mathrm{Fe}^{3+}(0,978-1,442$ apfu) nos sítios octaédricos Y. Apenas três análises ocupam o campo do epídoto férrico (Figura 12A). Já no diagrama ternário para nomenclatura de minerais do Grupo do Epídoto que leva com conta os conteúdos de $\mathrm{Fe}^{3+}, \mathrm{M}^{2+}\left(=\mathrm{Fe}^{2+}+\mathrm{Mn}^{2+}+\mathrm{Mg}\right)$ e $\mathrm{Al}$ [30], as amostras exibem um trend de enriquecimento em alumínio, afastando-se do polo composicional do epídoto em direção ao campo da clinozoisita (Figura 12B).

(A)

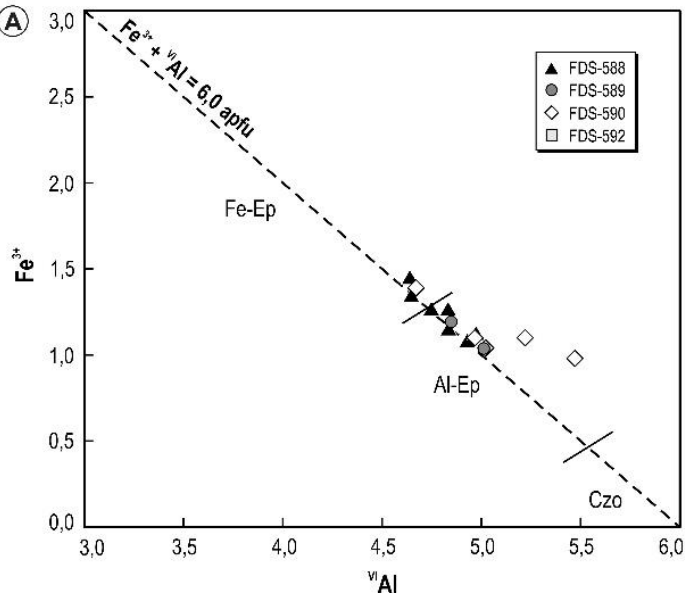

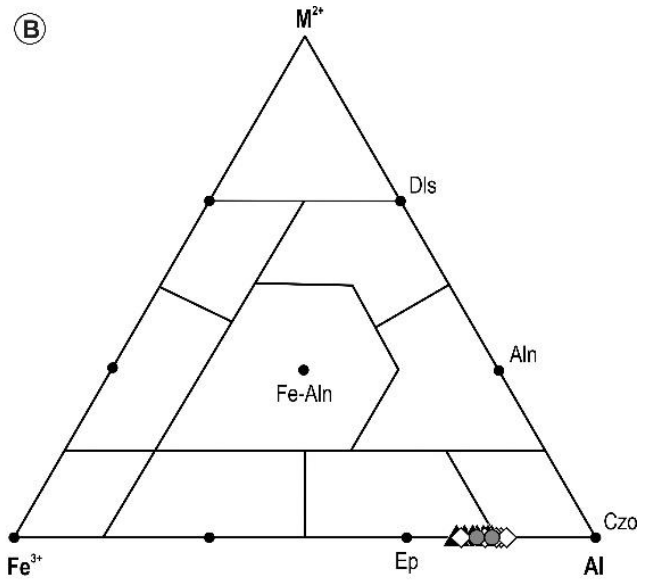

Figura 12. Esquemas de classificação e nomenclatura de minerais do Grupo do Epídoto. (A) Projeção $\mathrm{Fe}^{3+}$ versus ${ }^{V I} \mathrm{Al}$ [29]. (B) Sistema ternário $\mathrm{Fe}^{3+}-\mathrm{M}^{2+}$-Al [30]. Epídoto (Ep), Epídoto férrico (Fe-Ep), Epídoto aluminoso (Al-Ep), Clinozoisita (Czo), Allanita (Aln), Ferro-Allanita (Fe-Aln), Dolaseíta (Dls).

Alguns autores [e.g. 31, 32] têm utilizado a composição química do epídoto para inferir sua natureza primária ou hidrotermal. $\mathrm{O}$ teor do componente pistacita $\left[\mathrm{Ps}=\mathrm{Fe}^{3+} /\left(\mathrm{Fe}^{3+}+\mathrm{Al}\right)\right]$ é o parâmetro utilizado para este fim e representa o membro final férrico na série de solução sólida epídoto-clinozoisita. Segundo Tulloch (1979) [31], cristais de epídoto formados a partir da alteração de plagioclásio apresentam $\mathrm{Ps}_{0-24}$. O conteúdo de pistacita varia entre $\mathrm{Ps}_{25-29}$ nos cristais de origem magmática e entre $\mathrm{Ps}_{36-48}$ naqueles gerados a partir da alteração da biotita. 
Os teores de Ps nos cristais de epídoto do SLD variam entre 17 e 24\% (Figura 13), o que sugere uma origem hidrotermal associada a desestabilização do plagioclásio [31]. Contudo, valores similares aos obtidos nesse estudo foram reportados a epídotos inequivocamente magmáticos nos diques dacíticos de Front Range, no colorado ( $\mathrm{Ps}_{19-24}$ ) [33] e nas intrusões Glória Norte ( $\left.\mathrm{Ps}_{20-22}\right)$ [32] e Coronel João Sá ( $\left.\mathrm{Ps}_{18-25}\right)$ [34], no Domínio Macururé.

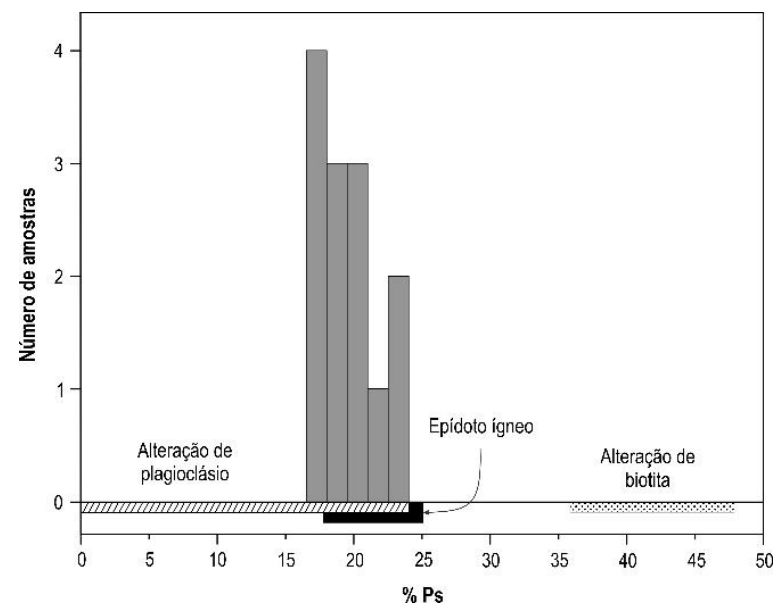

Figura 13. Distribuição da porcentagem de pistacita nos cristais de epídoto do Stock Lagoa de Dentro, em relação às variações composicionais observadas em epídoto de alteração [31] e magmático [34].

\subsection{Apatita}

Os cristais de apatita dos granitos do SLD apresentam-se com formas euédricas e hábito acicular, fazendo contatos retos com os demais minerais da rocha. Geralmente ocorrem como inclusões em feldspatos e micas, sugerindo cristalização em estágio magmático precoce.

As fórmulas estruturais da apatita foram calculadas com base em 25 ânions e os sítios foram preenchidos de acordo com a fórmula ideal $\mathrm{M}_{10}\left(\mathrm{ZO}_{4}\right)_{6} \mathrm{X}_{2}$ [35], desconsiderando a possibilidade de incorporação de $\mathrm{CO}_{3}$. A quantidade de $\mathrm{OH}$ foi calculada assumindo equilíbrio de carga em um sítio totalmente ocupado $(\mathrm{F}+\mathrm{Cl}+\mathrm{OH}=2$ apfu). Dados químicos representativos para os cristais de apatita do SLD são mostrados na tabela 4.

Os cristais de apatita investigados correspondem a fluorapatita, como é típico para a maioria das rochas ígneas [36]. O sítio $\mathrm{Z}$ destes cristais é ocupado por $\mathrm{P}$ (5,776-6,147 apfu) e, subordinadamente, por $\mathrm{Si}(0,069-0,176 \mathrm{apfu})$. Os cátions $\mathrm{Ca}$ e Na ocupam o sítio A com 9,476 a 10,237 apfu e 0,067 a 0,199 apfu, respectivamente. Os conteúdos de F no sítio X variam entre 1,039 e 1,649 apfu, enquanto os teores de $\mathrm{Cl}$, quando observados, não ultrapassam 0,261 apfu. Algumas análises apresentam baixas somas de $\mathrm{F}+\mathrm{Cl}$, que resultam em défice de carga na posição aniônica (0,351-0,961 apfu), sugerindo a presença de um significativo componente hidroxiapatita.

A variação composicional no sítio monovalente dos cristais de apatita do SLD é apresentada na figura $14 \mathrm{~A}$ em termos dos conteúdos molares de $\mathrm{F}, \mathrm{Cl}$ e $\mathrm{OH}$, que definem os polos puros fluorapatita (FAp), clorapatita (CAp) e hidroxiapatita (HAp), respectivamente. Os dados químicos dos cristais analisados agrupam-se ao longo dos vértices FAp e HAp, demarcando uma área aproximadamente similar à ocupada pela composição da apatita de muscovita granitos [37], diferindo apenas pelos maiores conteúdos de $\mathrm{OH}$. Resultados semelhantes são obtidos na projeção $\mathrm{P}-\mathrm{Si}-\mathrm{S}$ [37], onde as amostras se distribuem entre os vértices $\mathrm{P}$ e Si (Figura 14B).

Apatita com teores elevados de $\mathrm{F}$ e baixos de $\mathrm{Cl}$ são comumente descritas em granitos evoluídos [37, 38]. Em rochas híbridas, que não correspondem aos típicos granitos I ou S, este comportamento pode ser atribuído à abundância de halogêneos nas rochas-fonte de origem sedimentar, que sofrem perda preferencial de $\mathrm{Cl}$ durante os processos de intemperização, devido à alta solubilidade deste elemento em soluções aquosas [38]. Adicionalmente, a cristalização fracionada por si só também pode aumentar os conteúdos de $\mathrm{F}$ relativamente ao $\mathrm{Cl}$, resultando em altas razões $\mathrm{F} / \mathrm{Cl}$ nos fracionados magmáticos mais evoluídos [38]. 
Tabela 4. Análises químicas representativas de cristais de apatita. MAFG: Muscovita Álcali-Feldspato Granito, MG: Monzogranito.

\begin{tabular}{|c|c|c|c|c|c|c|c|c|c|c|c|c|c|}
\hline \multirow{2}{*}{$\begin{array}{l}\text { Amostra } \\
\text { Rocha } \\
\mathrm{P}_{2} \mathrm{O}_{5}\end{array}$} & \multicolumn{3}{|c|}{$\begin{array}{c}\text { FDS-588 } \\
\text { MAFG }\end{array}$} & \multicolumn{4}{|c|}{$\begin{array}{c}\text { FDS-590 } \\
\text { MAFG }\end{array}$} & \multicolumn{6}{|c|}{$\begin{array}{c}\text { FDS-592 } \\
\text { MG }\end{array}$} \\
\hline & 39,5 & 40,8 & 41,2 & 40,9 & 40,7 & 39,0 & 41,0 & 41,3 & 41,3 & 41,5 & 40,6 & 41,3 & 42,1 \\
\hline $\mathrm{SiO}_{2}$ & 0,8 & & & & 0,4 & 1,0 & & 0,5 & & & 0,4 & 0,6 & \\
\hline $\mathrm{FeO}$ & & & & & & 2,9 & & & & & & & \\
\hline $\mathrm{CaO}$ & 54,5 & 53,5 & 53,7 & 53,8 & 52,4 & 51,6 & 54,4 & 53,7 & 52,8 & 53,2 & 53,1 & 53,5 & 54,0 \\
\hline $\mathrm{Na}_{2} \mathrm{O}$ & & & & 0,4 & 0,4 & & & 0,5 & 0,2 & 0,3 & 0,3 & 0,5 & \\
\hline $\mathrm{F}$ & 2,6 & 2,8 & 2,5 & 2,4 & 3,0 & 2,8 & 2,0 & 2,0 & 2,8 & 2,8 & 2,8 & 2,0 & 1,9 \\
\hline $\mathrm{Cl}$ & & & 0,1 & & & & & & & & & & \\
\hline $\mathrm{H}_{2} \mathrm{O}$ & 0,5 & 0,4 & 0,5 & 0,6 & 0,3 & 0,4 & 0,8 & 0,8 & 0,4 & 0,4 & 0,4 & 0,8 & 0,8 \\
\hline Subtotal & 97,9 & 97,5 & 98,0 & 98,1 & 97,2 & 97,7 & 98,2 & 98,8 & 97,5 & 98,2 & 97,6 & 98,7 & 98,9 \\
\hline $\mathrm{O}=\mathrm{F}, \mathrm{Cl}$ & 1,1 & 1,2 & 1,1 & 1,0 & 1,3 & 1,2 & 0,9 & 0,9 & 1,2 & 1,2 & 1,2 & 0,9 & 0,8 \\
\hline Total & 96,8 & 96,3 & 96,9 & 97,1 & 95,9 & 96,5 & 97,4 & 98,0 & 96,3 & 97,0 & 96,4 & 97,9 & 98,1 \\
\hline$P$ & 5,822 & 6,010 & 6,025 & 5,987 & 6,004 & 5,803 & 5,982 & 5,969 & 6,063 & 6,052 & 5,971 & 5,970 & 6,063 \\
\hline $\mathrm{Si}$ & 0,139 & & & & 0,070 & 0,176 & & 0,085 & & & 0,069 & 0,102 & \\
\hline$[\mathrm{Z}]$ & 5,961 & 6,010 & 6,025 & 5,987 & 6,074 & 5,978 & 5,982 & 6,055 & 6,063 & 6,052 & 6,040 & 6,072 & 6,063 \\
\hline $\mathrm{Fe}$ & & & & & & 0,426 & & & & & & & \\
\hline $\mathrm{Ca}$ & 10,166 & 9,974 & 9,938 & 9,966 & 9,783 & 9,716 & 10,045 & 9,823 & 9,809 & 9,819 & 9,883 & 9,787 & 9,842 \\
\hline $\mathrm{Na}$ & & & & 0,134 & 0,135 & & & 0,166 & 0,067 & 0,100 & 0,101 & 0,166 & \\
\hline [M] & 10,166 & 9,974 & 9,938 & 10,100 & 9,918 & 10,142 & 10,045 & 9,988 & 9,877 & 9,919 & 9,984 & $\mathbf{9 , 9 5 3}$ & 9,842 \\
\hline $\mathrm{F}$ & 1,435 & 1,514 & 1,345 & 1,319 & 1,649 & 1,529 & 1,105 & 1,094 & 1,561 & 1,525 & 1,538 & 1,095 & 1,039 \\
\hline $\mathrm{Cl}$ & & & 0,029 & & & & & & & & & & \\
\hline $\mathrm{OH}$ & 0,565 & 0,486 & 0,626 & 0,681 & 0,351 & 0,471 & 0,895 & 0,906 & 0,439 & 0,475 & 0,462 & 0,905 & 0,961 \\
\hline$[\mathbf{X}]$ & 2,000 & 2,000 & 2,000 & 2,000 & 2,000 & 2,000 & 2,000 & 2,000 & 2,000 & 2,000 & 2,000 & 2,000 & 2,000 \\
\hline Total & 18,128 & 17,985 & 17,963 & 18,087 & 17,992 & 18,120 & 18,027 & 18,043 & 17,939 & 17,972 & 18,025 & 18,025 & 17,905 \\
\hline FAp & 72 & 76 & 67 & 66 & 82 & 76 & 55 & 55 & 78 & 76 & 77 & 55 & 52 \\
\hline CAp & & & 1 & & & & & & & & & & \\
\hline HAp & 28 & 24 & 31 & 34 & 18 & 24 & 45 & 45 & 22 & 24 & 23 & 45 & 48 \\
\hline
\end{tabular}

(A)

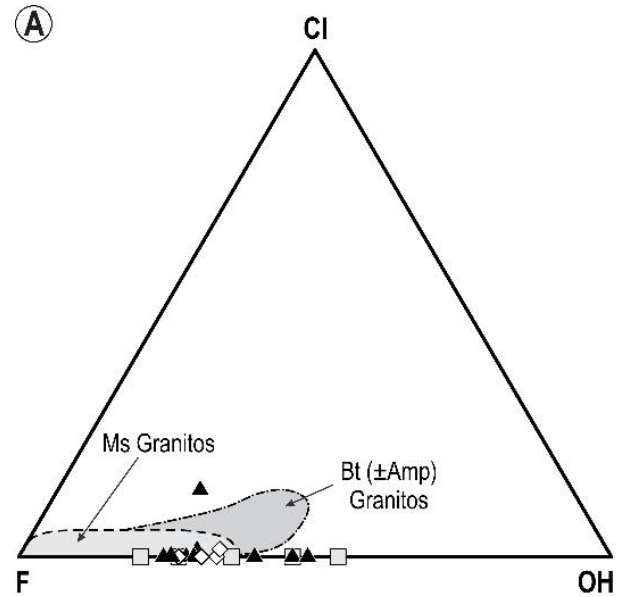

(B)

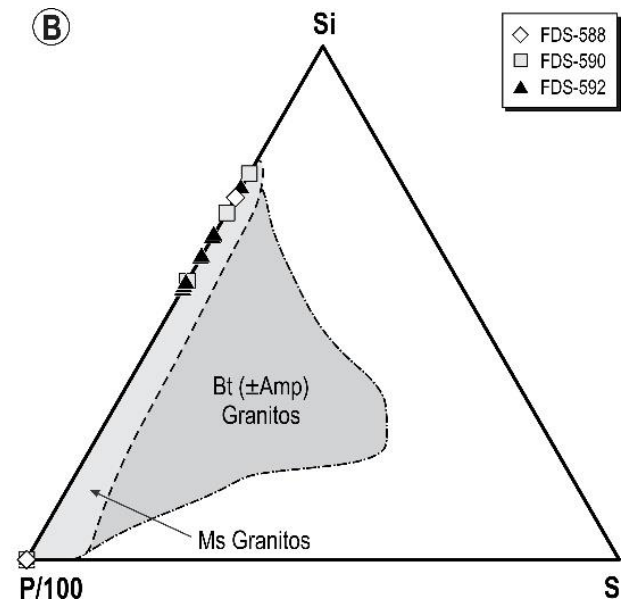

Figura 14. Variação composicional relativa dos cristais de apatita do Stock Lagoa de Dentro nos espaços (A) F-Cl-OH e (B) P-Si-S. Campos definidos por Teiber [37], com base em dados químicos de apatita de corpos ígneos da Austrália [38], Tibete [39], Alemanha e Grécia [40]. 


\subsection{Zircão}

Os cristais de zircão dos granitos do SLD ocorrem euédricos e fazem contatos retos com os outros minerais. Usualmente ocorrem em agregados que ocupam porções específicas na rocha, ora ao longo dos contatos entre minerais essenciais, ora inclusos por estes. Frequentemente são inclusos por albita e muscovita, minerais nos quais promove o desenvolvimento de halos pleocroicos.

Os cálculos da fórmula estrutural dos cristais analisados foram efetuados com base de 16 oxigênios e os sítios foram preenchidos de acordo com a fórmula geral $\mathrm{ABO}_{4}$ [41]. Análises químicas representativas obtidas para os cristais de zircão são apresentadas na tabela 5 .

Tabela 5. Análises químicas representativas de cristais de zircão. MAFG: Muscovita Álcali-Feldspato Granito, MMG: Muscovita Monzogranito, MG: Monzogranito.

\begin{tabular}{|c|c|c|c|c|c|c|c|c|c|c|c|c|c|}
\hline \multirow{2}{*}{$\begin{array}{l}\text { Amostra } \\
\text { Rocha } \\
\mathrm{SiO}_{2}\end{array}$} & \multicolumn{2}{|c|}{$\begin{array}{c}\text { FDS-588 } \\
\text { MAFG }\end{array}$} & \multicolumn{2}{|c|}{$\begin{array}{c}\text { FDS-589 } \\
\text { MMG }\end{array}$} & \multicolumn{3}{|c|}{$\begin{array}{c}\text { FDS-590 } \\
\text { MAFG }\end{array}$} & \multicolumn{6}{|c|}{$\begin{array}{c}\text { FDS-592 } \\
\text { MG }\end{array}$} \\
\hline & 32,1 & 30,6 & 31,4 & 30,7 & 30,6 & 30,0 & 31,8 & 30,9 & 32,4 & 31,9 & 31,1 & 31,1 & 31,1 \\
\hline $\mathrm{Al}_{2} \mathrm{O}_{3}$ & & 1,4 & & 2,0 & & & 0,3 & & & & & & \\
\hline $\mathrm{ZrO}_{2}$ & 65,4 & 65,7 & 63,6 & 63,1 & 66,0 & 64,8 & 65,4 & 64,3 & 65,5 & 64,2 & 65,1 & 66,0 & 65,5 \\
\hline $\mathrm{ThO}_{2}$ & 0,1 & 0,5 & & 1,5 & 0,7 & 0,8 & 0,1 & 0,5 & & 0,3 & 0,8 & 0,3 & 0,7 \\
\hline $\mathrm{UO}_{2}$ & 0,2 & 0,5 & 0,2 & 1,0 & 0,4 & 0,9 & 0,2 & 0,3 & 0,2 & 0,4 & 0,5 & 0,6 & 0,3 \\
\hline $\mathrm{HfO}_{2}$ & 1,5 & 1,2 & 2,0 & 1,6 & 2,3 & 2,7 & 1,8 & 3,1 & 1,3 & 2,5 & 2,1 & 1,7 & 1,6 \\
\hline $\mathrm{Nd}_{2} \mathrm{O}_{3}$ & & & & & & & & 0,9 & & & & & \\
\hline $\mathrm{Tm}_{2} \mathrm{O}_{3}$ & & & & & & & & & & & & 0,1 & 0,4 \\
\hline $\mathrm{Yb}_{2} \mathrm{O}_{3}$ & 0,7 & & 0,5 & & 0,1 & 0,6 & & 0,1 & 0,6 & 0,0 & 0,4 & 0,2 & 0,2 \\
\hline $\mathrm{FeO}$ & & & 2,3 & & & & & & & 0,7 & & & \\
\hline $\mathrm{CaO}$ & & & & & & & 0,3 & & & & & & \\
\hline $\mathrm{PbO}$ & & & & 0,1 & & 0,1 & & & & & & & \\
\hline Total & 100,0 & 99,9 & 100,0 & 100,0 & 100,1 & 99,9 & 99,9 & 100,1 & 100,0 & 100,0 & 100,0 & 100,0 & 99,8 \\
\hline $\mathrm{Si}$ & 3,972 & 3,799 & 3,889 & 3,821 & 3,842 & 3,815 & 3,932 & 3,888 & 3,994 & 3,956 & 3,898 & 3,885 & 3,896 \\
\hline $\mathrm{Al}$ & & 0,205 & & 0,293 & & & 0,044 & & & & & & \\
\hline [B] & 3,972 & 4,004 & 3,889 & 4,115 & 3,842 & 3,815 & 3,976 & 3,888 & 3,994 & 3,956 & 3,898 & 3,885 & 3,896 \\
\hline $\mathrm{Zr}$ & 3,946 & 3,977 & 3,841 & 3,830 & 4,041 & 4,019 & 3,943 & 3,945 & 3,938 & 3,882 & 3,979 & 4,020 & 4,001 \\
\hline Th & 0,003 & 0,014 & & 0,042 & 0,020 & 0,023 & 0,003 & 0,014 & & 0,008 & 0,023 & 0,009 & 0,020 \\
\hline $\mathrm{U}$ & 0,006 & 0,014 & 0,006 & 0,028 & 0,011 & 0,025 & 0,006 & 0,008 & 0,005 & 0,011 & 0,014 & 0,017 & 0,008 \\
\hline $\mathrm{Hf}$ & 0,053 & 0,043 & 0,071 & 0,057 & 0,082 & 0,098 & 0,064 & 0,111 & 0,046 & 0,088 & 0,075 & 0,061 & 0,057 \\
\hline $\mathrm{Nd}$ & & & & & & & & 0,040 & & & & & \\
\hline $\mathrm{Tm}$ & & & & & & & & & & & & 0,004 & 0,016 \\
\hline $\mathrm{Yb}$ & 0,026 & & 0,019 & & 0,004 & 0,023 & & 0,004 & 0,023 & & 0,015 & 0,008 & 0,008 \\
\hline $\mathrm{Fe}$ & & & 0,238 & & & & & & & 0,073 & & & \\
\hline $\mathrm{Ca}$ & & & & & & & 0,040 & & & & & & \\
\hline $\mathrm{Pb}$ & & & & 0,003 & & 0,003 & & & & & & & \\
\hline [A] & 4,034 & 4,048 & 4,175 & 3,960 & 4,159 & 4,192 & 4,055 & 4,123 & 4,011 & 4,062 & 4,106 & 4,118 & 4,110 \\
\hline$(\mathrm{Zr} / \mathrm{Hf})_{\mathrm{W}}$ & 38 & 48 & 28 & 34 & 25 & 21 & 32 & 18 & 44 & 22 & 27 & 34 & 36 \\
\hline
\end{tabular}

A posição A é ocupada por $\mathrm{Zr}(3,830-4,164 \mathrm{apfu})$ e, de forma subordinada, por Hf $(0,043-$ 0,098 apfu), U (0,005-0,028 apfu), Th (0,003-0,042 apfu), Fe (0,073-0,238 apfu), elementos terras-raras $(0,004-0,044 \mathrm{apfu})$ e $\mathrm{Pb}(<0,006 \mathrm{apfu})$. Já o sítio B acomoda $\mathrm{Si}(3,711-3,994 \mathrm{apfu})$ e $\mathrm{Al}(0,044-0,293 \mathrm{apfu})$.

Na maioria das rochas ígneas saturadas em sílica, o zircão é o principal mineral que contém háfnio, de modo que a razão $\mathrm{Zr} / \mathrm{Hf}$ pode ser interpretada como boa aproximação para esta relação no magma [42]. Na compilação de dados composicionais realizada por Pupin (2000) [42], a assinatura do zircão da crosta continental é marcada por valores $\mathrm{Zr} / \mathrm{Hf}$ entre 36 e 45 , diferindo significativamente das razões encontradas em cristais de zircão mantélicos, que variam de 60 a 68. Nos cristais de zircão do SLD as razões Zr/Hf variam entre 18 e 48, com valor médio de 30 . Esses valores são consistentes com os obtidos em outras suítes plutônicas peraluminosas [41, 43, 44] e estão em acordo com a assinatura de cristais de zircão anatéticos, derivados de fontes crustais ou principalmente crustais $[41,42]$. 


\subsection{Ilmenita}

A ilmenita foi o único mineral opaco identificado nas rochas do SLD. Seus cristais exibem formas anédricas a euédricas e fazem contatos curvos e retos com os outros minerais da rocha. Os cristais anédricos geralmente estão bordejados por titanita granular, originada a partir da alteração hidrotermal da ilmenita. Os cristais euédricos, todavia, ocorrem em associação com micas ou inclusos por feldspatos.

A fórmula estrutural dos cristais de ilmenita foi calculada com base em uma célula unitária de 6 oxigênios e os sítios foram preenchidos de acordo com a fórmula genérica ( $\mathrm{Fe}, \mathrm{Mg}, \mathrm{Mn}, \mathrm{Zn}) \mathrm{TiO}_{3}$ [45]. As concentrações de ferro férrico e ferro ferroso foram estimadas por estequiometria, usando o método de Droop (1987) [46]. Dados químicos representativos para a ilmenita estão listados na tabela 6.

Tabela 6. Análises químicas representativas de cristais de ilmenita. MAFG: Muscovita Álcali-Feldspato Granito, MG: Monzogranito.

\begin{tabular}{lrrrrrrrrrrr}
\hline $\begin{array}{l}\text { Amostra } \\
\text { Rocha }\end{array}$ & $\begin{array}{r}\text { FDS-588 } \\
\text { MAFG }\end{array}$ & \multicolumn{9}{c}{ FDS-590 } & \multicolumn{3}{c|}{ MAFG } & \multicolumn{3}{c}{ FDS-592 } \\
MG
\end{tabular}

Nos cristais de ilmenita estudados o Fe (1,367-1,890 apfu) ocorre apenas como um cátion bivalente, sugerindo que a cristalização das rochas do SLD se processou a partir de magmas reduzidos, com altas razões $\mathrm{Fe}^{2+} / \mathrm{Fe}^{3+}$ [38]. A ausência modal de magnetita, principal fase mineral hospedeira de $\mathrm{Fe}^{3+}$, corrobora esta interpretação e sugere que SLD pertence aos granitos da série ilmenita de Ishihara (1977) [47], o que implica cristalização sob baixas condições de fugacidade de oxigênio.

A ocupação do sítio do Fe é complementada por quantidades menores de Mn (0,039-0,255 apfu), Zn (0,019-0,377 apfu) e Ca (0,001-0,043 apfu). Os dados químicos dos cristais analisados foram alocados no sistema ternário $\mathrm{Mn}-\mathrm{Zn}-\mathrm{Fe}$, onde estão delimitadas as composições dos membros finais da solução sólida Pirofanita $\left(\mathrm{MnTiO}_{3}\right)$-Ecandrewsita $\left(\mathrm{ZnTiO}_{3}\right)$-Ilmenita $\left(\mathrm{FeTiO}_{3}\right)$. Conforme apresentado na figura 15 , o enriquecimento em $\mathrm{Zn}$ nas amostras é acompanhado pelo aumento dos conteúdos de Mn e decréscimo de Fe. Os teores dos componentes $\mathrm{MnTiO}_{3}$ e $\mathrm{ZnTiO}_{3}$ situam-se nos intervalos $\mathrm{Php}_{3-14}$ e $\mathrm{Ec}_{0-20}$, respectivamente, exibindo composição média $\mathrm{Ilm}_{87} \mathrm{Pph}_{6} \mathrm{Ec}_{7}$.

O enriquecimento do componente pirofanita em cristais de ilmenita de sistemas ígneos ácidos é reflexo da tendência geoquímica do Mn em se concentrar nos magmas mais evoluídos [48] devido à dificuldade de incorporação na estrutura de silicatos ferro-magnesianos e cálcicos, dado o tamanho do íon $\mathrm{Mn}^{2+}(0,80 \AA)$. Cristais de ilmenita ricos em $\mathrm{Zn}$, embora menos comuns, são tipicamente identificadas em granitos alcalinos $[45,49]$ e em rochas metamórficas de baixo a médio grau [50]. 




Figura 15. Diagrama $\mathrm{MnTiO}_{3}-\mathrm{ZnTiO}_{3}-\mathrm{FeTiO}_{3}$ para classificação de minerais do Grupo da Ilmenita, com a distribuição dos cristais de ilmenita do Stock Lagoa de Dentro [49].

\section{CONCLUSÃO}

O Stock Lagoa de Dentro, localizado na porção oriental do Sistema Orogênico Sergipano, é um dos representantes do magmatismo leucogranítico cálcio-alcalino de alto $\mathrm{K}$ presente no Domínio Macururé. Os dados de química mineral suportam a hipótese de contribuição crustal metassedimentar na origem do magma riolítico Lagoa de Dentro.

Os feldspatos do SLD são homogêneos em composição, não apresentando diferenças significativas entre os tipos petrográficos. O feldspato alcalino corresponde ao ortoclásio $\left(\mathrm{Or}_{92-97}\right)$ e o plagioclásio possui composição albítica $\left(\mathrm{An}_{1-7}\right)$, traduzindo o elevado grau de fracionamento das rochas estudadas.

As micas ocorrem nas variedades dioctaédrica e trioctaédrica, representadas por cristais de muscovita e biotita, respectivamente. As microtexturas sugerem que estes minerais se formaram nos últimos estágios de cristalização magmática e, posteriormente, sofreram reequilíbrio subsolidus, evidenciado pelos baixos conteúdos de $\mathrm{TiO}_{2}$ e variados graus cloritização e oxidação.

O distanciamento da composição ideal da muscovita observado nas rochas do SLD se deve, principalmente, à substituição fengítica, mecanismo de acomodação catiônica responsável pelo enriquecimento em Fe e Mg nos sítios octaédricos e em Si nas posições tetraédricas.

Os dados químicos obtidos para os cristais de biotita revelam composições enriquecidas na molécula de annita e caracterizam magmas transicionais entre os campos cálcio-alcalino e alumino-potássico, logo, compatível com o caráter subalcalino das rochas do SLD. Adicionalmente, os altos conteúdos de $\mathrm{Al}$ em coordenação octaédrica indicam a natureza aluminosa do magma progenitor.

Os teores de pistacita $\left(\mathrm{Ps}_{18-24}\right)$ estão de acordo os valores reportados para o epídoto magmático de outros plútons do Domínio Macururé, o que é corroborado pelas suas formas idiomórficas e ocorrência em íntima associação com biotita. Por outro lado, alguns destes cristais representam produtos de alteração hidrotermal do plagioclásio.

Os cristais da fluorapatita (FAp F1-82 apresentam composições similares àquelas de granitos peraluminosos à muscovita, enquanto o zircão exibe assinatura típica de rochas derivadas de fontes crustais.

A ocorrência de ilmenita como fase precoce, associada a ausência modal de magnetita permite classificar as rochas estudadas como granitos da Série Ilmenita, indicando condições de baixa fugacidade de oxigênio durante a cristalização do SLD. Esses cristais exibem composições enriquecidas nas moléculas de pirofanita $\left(\mathrm{Php}_{3-15}\right)$ e ecandrewsita $\left(\mathrm{Ec}_{0-20}\right)$. 


\section{AGRADECIMENTOS}

Este trabalho foi desenvolvido junto ao Laboratório de Petrologia Aplicada à Pesquisa Mineral da Universidade Federal de Sergipe (LAPA-UFS) e apresenta parte dos resultados do trabalho de conclusão de curso do primeiro autor. Os autores externam seus agradecimentos ao Conselho Nacional de Desenvolvimento Científico e Tecnológico (CNPq) pelo suporte financeiro desta pesquisa (Processos: 473013/2013-4 e 308059/2014-0). Agradecem igualmente à Superintendência de Salvador do Serviço Geológico do Brasil (CPRM) pelo apoio na confecção das lâminas delgadas, bem como aos revisores do artigo pelas sugestões e comentários pertinentes.

\section{REFERÊNCIAS BIBLIOGRÁFICAS}

1. Conceição JA, Rosa MLS, Conceição H. Sienogranitos leucocráticos do Domínio Macururé, Sistema Orogênico Sergipano, Nordeste do Brasil: Stock Glória Sul. Brazilian Journal of Geology. 2016 Mar; 46(1):63-77, doi:10.1590/2317-4889201620150044

2. Brito Neves BB, Sial AN, Albuquerque JPT. Vergência centrífuga residual no Sitema de Dobramentos Sergipano. Revista Brasileira de Geociências. 1977;7:102-114

3. Davison I, Santos RA. Tectonic Evolution of the Sergipano Fold Belt, NE Brasil, during Brasiliano Orogeny. Precambrian Research. 1989 Dec;45(4):319-342, doi:10.1016/0301-9268(89)90068-5

4. D'el-Rey Silva LJH. Basin infilling in the southern-central part of the Sergipano Belt (NE Brazil) and implications for the evolution of Pan-African/Brasiliano cratons and Neoproterozoic sedimentary cover. Journal of South American Earth Sciences. 1999 Sep;12(5):453-470, doi:10.1016/S08959811(99)00034-6

5. Oliveira EP. Faixa de Dobramento Sergipana. In: Barbosa JSF. Geologia da Bahia: pesquisa e atualização. Salvador: CBPM; 2012. p. 179-198.

6. Humphrey L, Allard GO. O Geossinclinal de Propriá - província tectônica do pré-cambriano posterior, recém descoberta no escudo brasileiro. Boletim Técnico da Petrobrás. 1967 Jul/Dez;10(3/4):409-430

7. Humphrey FL, Allard GO. Geologia da área do domo de Itabaiana (Sergipe) e sua relação com a geologia do geossinclinal de Propriá; um elemento tectônico recém-reconhecido no escudo brasileiro Rio de Janeiro: PETROBRÁS/CENPES; 1969. 160 p.

8. Silva Filho M, Bomfim LFC, Santos RA, Leal RA, Santana AC, Filho PAB. Geologia da Geossinclinal Sergipana e do seu embasamento Alagoas, Sergipe e Bahia: Projeto Baixo São Francisco/Vaza Barris. Brasília: DNPM/CPRM; 1979. 134 p.

9. Santos RA, Filho NRM, Souza JD. Programa de Levantamentos Geológicos Básicos do Brasil: Carta geológica, metalogenética/previsional - Escala 1:100.000 (Folha SC.24-Z-A-III Carira) Estados de Sergipe e Bahia. Brasília: DNPM/CPRM; 1988. 124 p.

10. Santos RA, Matins AAM, Neves JP, Leal RA. Geologia e Recursos Minerais do Estado de Sergipe: Texto Explicativo do Mapa Geológico do Estado de Sergipe (Escala 1:250.000). Brasília: CPRM/DIEDIG/DEPAT/CODISE; 1998. 156 p.

11. Chaves JM, Celino JJ. A operação dos mecanismos da tectônica de placas a luz de critérios geoquímicos dos granitoides da Faixa Sergipana. In: I Simpósio Regional de Geologia Bahia-Sergipe; 1992 May 04-07; Salvador: Sociedade Brasileira de Geologia. p. 42-45.

12. Oliveira EP, Bueno JF, McNaughton NJ, Silva Filho AF, Nascimento RS, Donatti-Filho JP. Age, composition, and source of continental arc- and syn-collision granites of the Neoproterozoic Sergipano Belt, Southern Borborema Province, Brazil. Journal of South American Earth Sciences. 2015;58:257280, doi:10.1016/j.jsames.2014.08.003.

13. Souza JD, Santos RA. Mapa geológico do estado de Sergipe (Escala 1:250.000). Salvador: CPRM/CODISE; 1997.

14. Streckeisen A. To each plutonic rocks its proper name. Earth Science Reviews. 1976 Mar;12(1):1-33, doi:10.1016/0012-8252(76)90052-0.

15. Pereira FS, Conceição JA, Rosa MLS, Conceição H. Stock Lagoa de Dentro, Domínio Macururé, Sistema Orogênico Sergipano: Geologia, Petrografia e Geoquímica. Scientia Plena. 2017 Feb;13(2):113, doi:10.14808/sci.plena.2017.025302.

16. Deer WA, Howie RA, Zussman J. An introduction to the rock-forming minerals. 2nd ed. Harlow: Longman Scientific \& Technical; 1992. 695 p.

17. Tindle AG, Webb PC. Estimation of lithium contents in trioctahedral micas using microprobe data: application to micas from granitic rocks. European Journal of Mineralogy. 1990;2(5):595-610, doi:10.1127/ejm/2/5/0595. 
18. Guidotti CV. Micas in metamorphic rocks. Reviews in Mineralogy and Geochemistry. 1984 Jan;13(1):357-467.

19. Foster MD. Layer charge relations in the dioctahedral and trioctahedral micas. The American Mineralogist. 1960 Mar/Apr;45:383-398.

20. Miller CF, Stoddard EF, Bradfish LJ, Dollase WA. Composition of plutonic muscovite: genetic implications. Canadian Mineralogist. 1981 Feb;19(1):25-34.

21. Monier G, Robert JL. Muscovite solid solutions in the system $\mathrm{K}_{2} \mathrm{O}-\mathrm{MgO}-\mathrm{FeO}-\mathrm{Al}_{2} \mathrm{O}_{3}-\mathrm{SiO}_{2}-\mathrm{H}_{2} \mathrm{O}$ : an experimental study at $2 \mathrm{kbar} \mathrm{PH}_{2} \mathrm{O}$ an comparison with natural $\mathrm{Li}$-free white micas. Mineralogical Magazine. 1986 Jun;50(356):257-266, doi:10.1180/minmag.1986.050.356.08.

22. Speer JA. Micas in igneous rocks. Reviews in Mineralogy and Geochemistry. 1984 Jan;13(1):299-356.

23. Foster MD. Interpretation of the composition of trioctahedral micas. Washington: United States Government Printing Office; 1960. 43 p.

24. Guidotti CV, Dyar MD. Ferric iron in metamorphic biotite and its petrologic and crystallochemical implications. American Mineralogist. 1991 Jan/Feb;76:161-175.

25. Whalen JB, Chappell BW. Opaque mineralogy and mafic mineral chemistry of I- and S-type granites of the Lachlan fold belt, southeast Australia. American Mineralogist. 1988 Mar/Apr;73:281-296.

26. Nachit H, Razafimahefa N, Stussi JM, Caron JP. Composition chimique des biotites et typologie magmatique des granitoïdes. Comptes Rendus C R Acad Sci Paris. 1985;301:813-818.

27. Abdel-Rahman AFM. Nature of biotites from alkaline, calc-alkaline, and peraluminous magmas. Journal of Petrology. 1994 Apr;35(2):525-541, doi:10.1093/petrology/35.2.525.

28. Nachit H, Ibhi A, Abia EH, Ohoud MB. Discrimination between primary magmatic biotites, reequilibrated biotites and neoformed biotites. Comptes Rendus Geoscience. 2005;337:1415-1420, doi:10.1016/j.crte.2005.09.002.

29. Holdaway MJ. Thermal stability of $\mathrm{Al}-\mathrm{Fe}$ epidote as a function of $\mathrm{fO}_{2}$ and $\mathrm{Fe}$ content. Contributions to Mineralogy and Petrology. 1972 Mar;37(4):307-340, doi:10.1007/BF00371011.

30. Kartashov PM. Classification diagram for REE-bearing members of the epidote group based on crystallochemical data. In: Workshop on acessory minerals; 2014 Sep; University of Warsaw. p. 19-21, doi:10.13140/2.1.4907.0089.

31. Tulloch AJ. Secondary Ca-Al silicates as low-grade alteration products of granitoid biotite. Contributions to Mineralogy and Petrology. 1979 Jun;69(2):105-117, doi:10.1007/BF00371854.

32. Sial AN, Vasconcelos PM, Ferreira VP, Pessoa RR, Brasilino RG, Neto JMM. Geochronological and mineralogical constraints on depth of emplacement and ascencion rates of epidote-bearing magmas from northeastern Brazil. Lithos. 2008;105:225-238, doi:10.1016/j.lithos.2008.04.002.

33. Evans BW, Vance JA. Epidote phenocrysts in dacitic dikes, Boulder County, Colorado. Constributions to Mineralogy and Petrology. 1987;96:178-185.

34. Long LE, Castallana CH, Sial AN. Age, Origin and Cooling History of the Coronel João Sá Pluton, Bahia, Brazil. Journal of Petrology. 2005;46(2):255-273, doi:10.1093/petrology/egh070.

35. Pan Y, Fleet ME. Compositions of the apatita-group minerals: substitutions mechanisms and controlling factors. Reviews in Mineralogy and Geochemistry. 2002;48(1):13-49, doi:10.2138/rmg. 2002.48.2.

36. Piccoli PM, Candela PA. Apatite in igneous systems. Reviews in Mineralogy and Geochemistry. 2002 Jan;48(1):255-292, doi:10.2138/rmg.2002.48.6.

37. Teiber H, Marks MAW, Arzamastsev AA, Wenzel T, Markl G. Compositional variation in apatite from various host rocks: clues with regards to source composition and crystallization conditions. Journal of Mineralogy and Geochemistry. 2015 Feb;192(2):151-167, doi:10.1127/njma/2015/0277.

38. Sha LK, Chappell BW. Apatite chemical composition, determined by electron microprobe and laserablation inductively coupled plasma mass spectrometry, as a probe into granite petrogenesis. Geochimica et Cosmochimica Acta. 1999;63(22):3861-3881, doi:10.1016/S0016-7037(99)00210-0.

39. Chu MF, Wang KL, Griffin WL, Chung SL, O'reilly SY, Pearson NJ, et al. Apatite composition: tracing petrogenetic processes in transhimalayan granitoids. Journal of Petrology. 2009;50(10):18291855, doi:10.1093/petrology/egp054.

40. Teiber H, Marks MAW, Wenzel T, Siebel W, Altherr R, Markl G. The distribution of halogens (F, Cl, $\mathrm{Br}$ ) in granitoid rocks. Chemical Geology. 2014;374-375:92-109, doi:10.1016/j.chemgeo.2014.03. 006.

41. Pérez-Soba C, Villaseca C, González del Tánago J, Nasdala L. The composition of zircon in the peraluminous hercynian granites of the Spanish Central System Batholith. The Canadian Mineralogist. 2007;45(3):509-527, doi:10.2113/gscanmin.45.3.509.

42. Pupin JP. Granite genesis related to geodynamics from Hf-Y in zircon. Transactions of the Royal Society of Edinburgh: Earth Sciences. 2000;91:245-256. 
43. Broska I, Kubiš M, Williams CT, Konečný P. The compositions of rock-forming and accessory minerals from the Gemeric granites (Hnilec area, Gemeric Superunit, Western Carpathians). Bulletin of the Czech Geological Survey. 2002;77(2):147-155.

44. Martins HCB, Abreu J. The composition of zircon in Variscan granites from Northern Portugal. Estudios Geológicos. 2014 Dec;70(2):1-9, doi:10.3989/egeol.41729.318.

45. Suwa K, Enami M, Hiraiwa I, Yang T. Zn-Mn ilmenite in the Kuiqi Granite from Fuzhou Fujian Province, East China. Mineralogy and Petrology. 1987;36:111-120, doi:10.1007/BF01164484.

46. Droop GTR. A general equation for estimating $\mathrm{Fe}^{3+}$ concentrations in ferromagnesian silicates and oxides form microprobe analyses, using stoichiometric criteria. Mineralogical Magazine. 1987 Sep;51:431-435.

47. Ishihara S. The magnetite-series and ilmenite-series granitic rocks. Mining Geology. 1977;27:293-305.

48. Mitchell RH, Liferovich RP. Ecandrewsite-zincian pyrophanite from lujavrite, Pilansberg Alkaline Complex, South Africa. The Canadian Mineralogist. 2004;42(4):1169-1178, doi:10.2113/gscanmin. 42.4.1169.

49. Snetsinger KG. Manganoan ilmenite from a Sierrian Adamellite. The American Mineralogist. 1969 Mar/Apr;54:431-436.

50. Whitney DL, Hirschmann M, Miller MG. Zincian ilmenite-ecandrewsite from pelitic schist, Death Valley, California, and the paragenesis of $(\mathrm{Zn}, \mathrm{Fe}) \mathrm{TiO}_{3}$ solid solution in metamorphic rocks. Canadian Mineralogist. 1993 Jun;31(2):425-436. 